\title{
Improving phosphorus use efficiency in agriculture: opportunities for breeding
}

\author{
Clemens C. M. van de Wiel • C. Gerard van der Linden • Olga E. Scholten
}

Received: 13 July 2015/Accepted: 26 September 2015/Published online: 16 October 2015

(C) The Author(s) 2015. This article is published with open access at Springerlink.com

\begin{abstract}
Phosphorus (P) is often an important limiting factor for crop yields, but rock phosphate as fertilizer is a non-renewable resource and expected to become scarce in the future. High $\mathrm{P}$ input levels in agriculture have led to environmental problems. One of the ways to tackle these issues simultaneously is improving phosphorus use efficiency (PUE) of the crops through breeding. In this review, we describe plant architectural and physiological traits important for PUE. Subsequently, we discuss efficient methods of screening for PUE traits. We address targeted cultivation methods, including solid and hydroponic systems, as well as testing methods, such as image analysis systems, and biomass and photosynthesis measurements. Genetic variation for PUE traits has been assessed in many crops, and genetics of PUE has been studied by quantitative trait loci (QTL) analyses and genome-wide association study. A number of genes involved in the plant's response to low $\mathrm{P}$ have been characterized. These genes include transcription factors, and genes involved in signal transduction, hormonal pathways, sugar signalling, $\mathrm{P}$ saving metabolic pathways, and in $\mathrm{P}$
\end{abstract}

Electronic supplementary material The online version of this article (doi:10.1007/s10681-015-1572-3) contains supplementary material, which is available to authorized users.

C. C. M. van de Wiel $(\varangle)$. C. G. van der Linden ·

O. E. Scholten

Wageningen UR Plant Breeding, P.O. Box 386,

6700 AJ Wageningen, The Netherlands

e-mail: clemens.vandewiel@wur.nl scavenging, including transporters and metabolites and/or ATP-ases mobilizing P in the soil. In addition, the role of microorganisms promoting PUE of plants, particularly arbuscular mycorrhizal fungi is discussed. An overview is given of methods for selecting for optimal combinations of plant and fungal genotypes, and their genetics, incl. QTLs and genes involved. In conclusion, significant progress has been made in selecting for traits for PUE, developing systems for the difficult but highly relevant root phenotyping, and in identifying QTLs and genes involved.

Keywords Breeding $\cdot$ Mycorrhiza $\cdot$ Nutrient use efficiency $\cdot$ Phosphorus $\cdot$ Plant phenotyping $\cdot$ Root architecture

\section{Introduction}

Phosphorus is an essential nutrient for plant growth, but uptake from soil can be difficult and an important limiting factor in achieving optimal yields in agriculture (Smit et al. 2009). Even when present in the soil in higher amounts, phosphorus availability to plants is often still problematic because of the phosphatebinding capacity of several types of soil (Syers et al. 2008). About $30 \%$ of soil worldwide shows a high phosphate-fixing capacity, e.g. in southern China, Brazil and Sub-Saharan Africa (Kochian 2012).

Phosphorus limitation is usually overcome by the application of Pi-containing fertilizer, but such 
phosphorus is basically from a non-renewable resource (Vaccari 2009). The primary Pi source of fertilizer is rock $\mathrm{Pi}$, which is minable in only a few places in the world. A single country, Morocco, possesses $85 \%$ of known remaining reserves. Though estimated amounts are not likely running out in the short term, rock Pi will become scarce, at least in terms of pricing due to increased demand. Analogous to developments in another non-renewable resource, oil, researchers have indicated "peak-phosphorus", which is expected to occur as early as around 2030 (Cordell et al. 2009), but other studies extend predicted $\mathrm{P}$ depletion to 2100 or two to three centuries beyond (Sattari et al. 2012). Expected future scarcity is already reflected in that the US and China have stopped export for strategic reasons. China is presently the largest producer of $\mathrm{P}$ with $37.5 \%$ of world production in 2010 (Sattari et al. 2014). The Hague Centre for Strategic Studies recently pointed out that the EU is particularly vulnerable to market availability of rock $\mathrm{Pi}$ as it is almost entirely dependent on imports from the rest of the world (De Ridder et al. 2012). In addition, rock Pi quality is variable. For instance, Rock Pi can contain heavy metals such as cadmium that may accumulate in arable soils as a result of the addition of rock Pi.

On the other hand, in present intensive agriculture, the copious use of $\mathrm{Pi}$, partly derived from local surpluses of manure from intensive livestock production presents a major environmental problem. It has led to emissions of phosphate to surface waters, including seas and oceans, resulting in harmful algal blooms (Ashley et al. 2011). This problem has been tackled with some success, but for instance in the Netherlands, still half of the monitored sites show values not in line with recent EU standards. Moreover, in bringing down Pi supply, levels where Pi again may become limiting for yields may soon be reached in some crops (Russchen et al. 2012).

There are several strategies to address the need to restrict the use of $\mathrm{Pi}$ and to avoid $\mathrm{Pi}$ depletion in the future at the same time. Pi could be recycled from various sources, e.g. waste water and manure. Pi could also be applied more efficiently by precision fertilization, e.g. using Pi amounts based on soil parameters for phosphate availability to plants or in-row application of Pi at optimal time periods, tailored to the requirements of the plants. Present estimates are that plants use only 10-25\% of applied Pi (Syers et al. 2008), indicating that there is room for improvement.
Another approach is improving phosphorus use efficiency (PUE) of the crops themselves by genetic means, i.e. by plant breeding. Based on their soil $\mathrm{P}$ model, Sattari et al. (2012) indicate that in many parts of the world residual soil $\mathrm{P}$ from intensive fertilization in the past will contribute significantly to crop production for a considerable period of time. An increased plant capacity to use that residual $\mathrm{P}$ efficiently will be helpful in that.

In this review, the possibilities of breeding for PUE are explored. First, an account will be given of plant traits relevant to PUE that could be amenable to selection, most of which can be found in plant architecture and physiology. Next, the availability and development of breeding tools and strategies will be discussed: (1) efficient screening/phenotyping techniques for selection for PUE in plants, (2) the genetics of PUE, i.e. identification of QTLs and genes involved, and the possibility of applying markerassisted selection and biotechnological methods, (3) the use of mycorrhiza, which main asset is thought to be making available phosphorus to plants in exchange for carbon compounds for its own growth.

\section{Traits important for breeding for PUE}

Phosphorus is an important component of plants, particularly in energy carriers, nucleic acids and signalling pathway proteins (like protein kinases). Phosphorus is important to the energy-demanding nitrogen fixing process in leguminous crops (Vance et al. 2003) and therefore indirectly also to availability for this other often yield-limiting nutrient, nitrogen. For plants, phosphate uptake from the soil is often difficult: in alkaline soils, $\mathrm{P}$ is bound to calcium and in acidic soils, $\mathrm{P}$ is usually bound to aluminium and/or iron (Kochian et al. 2004), in addition, organic material present in the soil (e.g. from manure or crop debris) can also bind phosphate, in particular phytate (inositol compounds). With the present aims of bringing down Pi fertilization levels, crops will need to mobilize residual soil phosphorus, and this may limit crop yields and thus efficient land use. For crops such as carrot, onion, several vegetables, potato and maize, the $\mathrm{P}$ fertilization standards for the Netherlands in the near future are expected to affect yields (Russchen et al. 2012). Several parameters are used to measure available and mobilizable $\mathrm{P}$ in the soil (e.g. 
$\mathrm{P}-\mathrm{CaCl}_{2}$ and $\mathrm{P}-\mathrm{Olsen}$ or a more recent variant, $\mathrm{P}-\mathrm{AL}$, respectively, see Table 1 for an overview of parameters in use). However, there is uncertainty to what extent these are representative of what can be utilized by specific plant species, particularly with regard to mobilization from organic matter.

PUE is based on a complex set of plant traits. For improving breeding success, it is important to break down this complexity into component traits that can be assessed efficiently for a particular crop species and that show consistent contributions to PUE. Moreover, these traits should preferably show an as simple as possible inheritance in order to be able to introduce PUE in elite plant material efficiently. Overall, two important basic mechanisms of PUE can be distinguished: the plant's ability to take up $\mathrm{P}$ from the soil and the efficiency of allocation/mobilization of $\mathrm{P}$ within the plant for sustaining biomass production, often referred to as external and internal PUE, respectively. Particularly for soils rich in bound $\mathrm{P}$, optimizing $\mathrm{P}$ scavenging would be an attractive breeding aim. In the end, a balance is needed in the phosphorus cycle, that is, $\mathrm{P}$ uptake by harvested crops and $\mathrm{P}$ fertilization should be in equilibrium to avoid soil P depletion (Lynch 2007; Richardson et al. 2011). Therefore, in the long term, internal P use efficiency, though likely more complex, would be a valuable breeding goal (Rose and Wissuwa 2012). Also here, a balance is needed with nutritional quality in terms of $\mathrm{P}$ availability. For instance, in extensively used nutrientpoor grasslands in Northern Australia, P can become limiting for cattle growth (McIvor et al. 2011). On the other hand, high concentrations of phosphorus in grains may not be needed in human and animal nutrition, the more so as long as most of the $\mathrm{P}$ is in an indigestible form, phytate, and thus does not contribute to direct uptake but only to waste problems by high levels of P in excrements (Rose et al. 2010).

In the following sections, traits that have been reported to be involved in PUE are discussed for their possible value to breeding, before looking at the ways these traits could be put to use in breeding research. First, plant architectural traits will be discussed. Architectural traits that are obviously relevant to

Table 1 Various parameters for assessing soil P available to plants from Russchen et al. (2012) and other references where indicated

\begin{tabular}{|c|c|c|}
\hline Parameter & Method & Comments \\
\hline P-Total & Destructive method using boiling in $\mathrm{H}_{2} \mathrm{SO}_{4}$ & Too crude for assessing plant availability \\
\hline P-Olsen & Extraction using $0.5 \mathrm{M} \mathrm{NaHCO}_{3}$ at $\mathrm{pH} 8.5$ & $\begin{array}{l}\text { Suitable for alkaline \& neutral soils, indicator of } P \text { capacity }(P \\
\text { potentially accessible to the plant, in this case } P \text { bound to } \mathrm{Ca})\end{array}$ \\
\hline $\mathrm{P}-\mathrm{Al}$ & $\begin{array}{l}\text { 1:20 (w/w) extraction using } 0.1 \mathrm{M} \\
\text { ammonium lactate \& } 0.2 \mathrm{M} \text { acetic acid at } \\
\mathrm{pH} 3.75\end{array}$ & Indicator of $\mathrm{P}$ capacity ( $\mathrm{P}$ potentially accessible to the plant) \\
\hline P-CAL & $\begin{array}{l}1: 20(\mathrm{w} / \mathrm{w}) \text { extraction using } 0.1 \mathrm{M} \mathrm{Ca} \text { lactate, } \\
0.1 \mathrm{M} \mathrm{Ca} \text { acetate, } 0.3 \mathrm{M} \text { acetic acid, } \mathrm{pH} 4.1\end{array}$ & Variant of P-Al by Schüller (1969) \\
\hline $\mathrm{P}_{\mathrm{w}}$ & 1:60 (w/w) extraction using water & $\begin{array}{l}\text { Indicator of a combination of } \mathrm{P} \text { capacity and } \mathrm{P} \text { directly available } \\
\text { to the plant (lower reproducibility than } \mathrm{P}-\mathrm{Al} \text { ) }\end{array}$ \\
\hline $\mathrm{P}-0.01 \mathrm{M} \mathrm{CaCl} 2$ & Extraction using $0.01 \mathrm{M} \mathrm{CaCl}_{2}$ & Indicator of $\mathrm{P}$ directly available to the plant \\
\hline Resin-P & $\begin{array}{l}\text { Extraction using deionised water \& AER } \\
\text { anion/CER cation strips }\end{array}$ & $\begin{array}{l}\text { Sequential method by Hedley et al. (1994), step 1, indicator of } \\
\text { inorganic P directly available to the plant }\end{array}$ \\
\hline $\mathrm{NaOH}-\mathrm{P}_{\mathrm{i}}$ & Extraction using $0.1 \mathrm{M} \mathrm{NaOH}$ & $\begin{array}{l}\text { Sequential method by Hedley et al. (1994), step 2, indicator of } \\
\text { inorganic P associated with positively-charged oxide surfaces }\end{array}$ \\
\hline $\mathrm{NaOH}-\mathrm{P}_{\mathrm{o}}$ & $\begin{array}{l}\text { Extraction from } \mathrm{NaOH}-\mathrm{Pi} \text { fraction using } \\
\text { conc. } \mathrm{H}_{2} \mathrm{SO}_{4} \& \mathrm{H}_{2} \mathrm{O}_{2}\end{array}$ & $\begin{array}{l}\text { Sequential method by Hedley et al. (1994), step 3, indicator of } \\
\text { labile (more easily accessible) organic P }\end{array}$ \\
\hline $\mathrm{H}_{2} \mathrm{SO}_{4}-\mathrm{P}$ & $\begin{array}{l}\text { Extraction from NaOH- } P_{i} \text { fraction using } \\
0.5 \mathrm{M} \mathrm{H}_{2} \mathrm{SO}_{4}\end{array}$ & $\begin{array}{l}\text { Sequential method by Hedley et al. (1994), step 4, indicator of P } \\
\text { associated with negatively-charged oxide surfaces through } \\
\text { exchangeable cations \& P held within oxide crystals }\end{array}$ \\
\hline Residual-P & $\begin{array}{l}\text { extraction of remaining soil residue using } \\
\text { conc. } \mathrm{H}_{2} \mathrm{SO}_{4} \& \text { heated } \mathrm{H}_{2} \mathrm{SO}_{2}\end{array}$ & $\begin{array}{l}\text { Sequential method by Hedley et al. (1994), step 5, indicator of } \\
\text { remainder of inaccessible P \& recalcitrant (poorly accessible) } \\
\text { organic P }\end{array}$ \\
\hline
\end{tabular}


external $\mathrm{P}$ efficiency are root traits related to $\mathrm{P}$ uptake. Subsequently, physiological characteristics will be discussed. Among these, traits are likely to be present that have relevance for internal $\mathrm{P}$ efficiency.

\section{Plant architectural traits related to PUE}

For optimal uptake of $\mathrm{P}$, root traits are obviously of importance. $\mathrm{P}$ deprivation usually leads to a higher root to shoot ratio and to changes in root architecture. An important contribution to scavenging the soil for $\mathrm{P}$ is root extension as the rhizosphere becomes quickly depleted of $\mathrm{P}$ and $\mathrm{P}$ repletion of this area by diffusion and mobilization usually does not keep pace with uptake. Moreover, $\mathrm{P}$ is often not evenly distributed in the soil. Several architectural changes are associated with higher PUE from roots. A higher number of lateral roots leads to improved possibilities of scavenging for P (Lynch 2007). Several traits will minimize the carbon cost of producing these lateral roots, including a thinner and more elongated morphology and anatomical features such as less secondary growth of the stele and aerenchyma in the cortex (Zhu et al. 2010). The increased lateral branching of the root is usually accompanied by a reduction of primary root development (Niu et al. 2013). Increase in axial root lengths, without increased lateral branching, has also been found in maize and common bean, and has been interpreted as explorative behaviour for soil patches enriched in $\mathrm{P}$ where lateral root formation then would become functional (Richardson et al. 2011). Modification of root hair growth can be achieved at relatively low carbon cost. Increased densities and lengths lead to increase P uptake capacity (Wang et al. 2004; Yan et al. 2004).

Since the top part of soils is often richer in $\mathrm{P}$, adaptations of root architecture that increase root density in the upper parts of the soil favour P uptake efficiency. This is achieved by a shallower growth angle of axial roots leading to a greater length of roots in the top soil. The legumes common bean and soybean can be selected for a higher basal root whorl number, that is, the side roots appearing in "rings" at the transition zone between shoot and main (tap) root (Lynch 2007). In addition, Wang et al. (2004) showed in soybean that root hair density and total length were higher in basal roots than tap roots while plant $\mathrm{P}$ concentration correlated positively with root hair density. They also showed a negative correlation between root hair density and average root hair lengths, which might be interpreted as a trade-off in terms of carbon use efficiency, that is, combining both high density and length for root hairs would be too costly in terms of carbon input. On the other hand, Yan et al. (2004) found both denser and longer root hairs in P-efficient genotypes of common bean. Apparently not all crops have the ability to increase root hair formation for increasing $\mathrm{P}$ uptake capacity. For example, onion mostly lacks this property (Itoh and Barber 1983; Liu et al. 2006). According to Ochoa et al. (2006), in some crops it will be helpful to enhance adventitious root formation (roots originating from other tissues, such as stems, e.g. crown roots from basal stem nodes in maize). However, increased adventitious root formation may come at the cost of less lateral rooting (Walk et al. 2006). Changes in the density and growth angle of lateral roots also increases scavenging capacity in the upper layer of the soil (Ao et al. 2010). Predominance of root surface investments in the upper soil layer may however have a trade-off with water use efficiency, as water will usually be more abundant in deeper layers under water-limiting conditions (Ho et al. 2005).

A special case are the proteoid roots (cluster roots: dense clusters of short side roots) found at low $\mathrm{P}$ in lupin and wild species of the Proteaceae family (Shane and Lambers 2005; Lambers et al. 2011, 2013). These are also most prominent in the upper soil layer and are thought to be mainly effective by mobilising $\mathrm{P}$ through exudation of organic acids rather than by scavenging through root extension (Rath et al. 2010, see also section on physiology below). Lupins combine this trait with an absence of mycorrhiza (with arbuscular mycorrhizal fungi (AMF), see further in section on mycorrhiza below).

Root architectural traits such as lateral branching and root hair density are clearly advantageous for PUE. However, monitoring these traits and using them for selection in breeding programs is certainly not straightforward. Various cultivation and phenotyping systems used for studying and monitoring roots are described in the section on phenotyping below.

Physiological traits related to PUE

As phosphorus is involved in many aspects of the plant's metabolism, a broad array of physiological traits is expected to be involved in PUE. Some of these 
improve $\mathrm{P}$ scavenging and uptake, e.g. by increasing transport capacity. Others promote a more economical use of $\mathrm{P}$ in plant growth, e.g. by optimising allocation within the plant. These strategies are often called external and internal PUE, respectively.

\section{External PUE: traits related to P uptake}

For improving $\mathrm{P}$ uptake, root exudates are thought to assist in mobilizing $\mathrm{P}$ from fixed sources in the soil (Vance et al. 2003). These exudates appear to be most effectively targeted to mobilizable $\mathrm{P}$ in the soil by the proteoid (cluster) roots in some lupin species (Rath et al. 2010). The exudates include protons and organic acids, such as citrate, malate, and oxalate. P-efficient genotypes of common bean were shown to have significantly higher levels of acid exudation than inefficient genotypes (Yan et al. 2004). Although the exudates can reach levels in the rhizosphere that are theoretically effective for releasing $\mathrm{P}$ from soil particles, there is uncertainty about their effectiveness. For instance, diffusion may be limited and they are often not targeted to areas in the soil with the highest $\mathrm{P}$ levels as effectively as by the cluster roots, but along the whole root (Pearse et al. 2007; Richardson et al. 2011). Organic acids can be quickly absorbed in acid soils and quickly degraded in calcareous soils (Wang et al. 2010). Between plant species there is also variation that is apparently not consistent with their expected role, e.g. despite exuding citrate, pea was shown not to be able to mobilize P from AlP and FeP (Pearse et al. 2007). In addition, there may be alternative mechanisms of action. In acid soils, organic acids may not necessarily improve P uptake directly, but they could also be effective by providing protection from Al toxicity to root growth in turn indirectly improving P uptake through a better developed root system (Delhaize et al. 2009). Organic acid exudation will also affect microorganisms involved in nutrient mobilisation.

Hydrolytic enzymes, such as acid phosphatases and ribonucleases, are upregulated in response to low $\mathrm{P}$ and upon exudation are able to release $\mathrm{P}$ fixed in organic forms in the soil, such as phytate (inositol hexakisphosphate) (Vance et al. 2003). For uptake of the $\mathrm{P}$ released, high-affinity transporters, transport proteins located in cell membranes, are important and are also up-regulated at low P.
Internal PUE: economical utilization of $P$ in the plant

Improving internal PUE will be leading to more resource-efficient use of $P$ than just increasing uptake of potentially scarce $P$, which was extensively reviewed by Veneklaas et al. (2012). A range of metabolic modifications is thought to be involved in internal $\mathrm{P}$ use efficiency. An important aspect is the effective mobilization of $\mathrm{P}$ within the plant, e.g. recycling $\mathrm{P}$ from mature/senescing plant parts to actively growing tissue and re-use of phosphate from vacuoles that have a buffering function in storing $\mathrm{P}$ when in excess of metabolic needs in the cytoplasm. Brassica cultivars with high PUE were shown to have efficient internal phosphate mobilization to active non-mature plant parts (Akhtar et al. 2008). At high P, up to $75 \%$ of $\mathrm{P}$ in leaves can be present as orthophosphate, most of which in the vacuoles (up to 85-95\% of cellular P, Akhtar et al. 2008). Nevertheless, upon $\mathrm{P}$ limitation photosynthesis is quickly affected, so there are apparently limitations to mobilization of this stored P (Richardson et al. 2011, also see below the effects of cytokinin signalling from the roots upon $\mathrm{P}$ limitation). Seedlings often depend on seed stores for $\mathrm{P}$ at early growth (White and Veneklaas 2012). At the same time, seed $P$ levels are not necessarily optimal to consumers, particularly so as seed $\mathrm{P}$ is mostly in the form of phytate, which is poorly metabolized by humans and monogastric animals (Veneklaas et al. 2012). Seed P concentrations have already been observed to have decreased with breeding efforts increasing harvest index (HI) in grains, but strategies aiming at improving PUE by drastically bringing down seed phytate levels often affect seed vigour. This may be compensated by targeted $\mathrm{P}$ fertilization, e.g. using seed coatings (Veneklaas et al. 2012). Phosphatases are not only involved in $P$ mobilization in the soil (see section "External PUE" above), but also in internal re-allocation in the plant and the latter involves specific types of phosphatases (Duff et al. 1994). Relatively little is known about specific internally localized phosphatases, but an example encoded by LaSAP1 was shown to be enhanced in expression by low $\mathrm{P}$ in roots of white lupin (Tang et al. 2013). Likewise, high-affinity transporters also appear to function in internal $\mathrm{P}$ mobilization, i.e. specific transporter genes were shown to be upregulated in senescing tissues (Veneklaas et al. 2012). 
Another strategy for internal PUE is adapting plant metabolism to a lower $\mathrm{P}$ requirement. One way is the replacement of phospholipids by sulfo- and/or galactolipids in membranes (Lambers et al. 2012). Cell walls are also adapted in response to low $\mathrm{P}$ conditions, i.e. by increased synthesis of P-free polysaccharides, such as cellulose (Rao and Terry 1995; Byrne et al. 2011). Another way is bypassing Pi- or ATP-demanding enzymes and/or metabolic pathways. In carbohydrate metabolism, several phosphorylated intermediates are produced, such as triose-P (glyceraldehyde-3-phosphate) in the carbon-fixation cycle. Under low $\mathrm{P}$, increased levels of starch in the plastids and sucrose in the cytosol at the cost of triose-P were observed in sugar beet (Rao et al. 1989; Rao and Terry 1995). On the other hand, members of the plant family Proteaceae growing on extremely P-poor soils did not show lower levels of the phosphorylated intermediate glucose 6-phosphate as found in the model plant Arabidopsis and crop species like barley and spinach under P limitation (Sulpice et al. 2014). However, the highest amount of internal $\mathrm{P}$ is present in the rRNA pool and the Proteaceae species studied showed low levels of rRNA, particularly of plastidic rRNA, at early leaf growth as compared to Arabidopsis. Apparently, these Proteaceae economize on the production of proteins, including enzymes involved in carbohydrate metabolism, instead of on P-containing metabolites. As a consequence, leaf growth and building up the photosynthetic machinery is separated in time during leaf development, the net result being a relatively high photosynthetic PUE in these Proteaceae species (Sulpice et al. 2014). Proteaceae also show far slower growth than crop plants, but elements from their economizing on P may be relevant as there are indications that e.g. Arabidopsis is not deploying the rRNA pool in young leaves efficiently under $\mathrm{P}$ stress (Sulpice et al. 2014).

The delayed greening observed in Proteaceae was accompanied by a reddish or yellow leaf colour that could also be offering protection against high light or defence against herbivory (Sulpice et al. 2014). Modulation of the phenylpropanoid pathway under $\mathrm{P}$ deficiency stress with the easily observable effect of anthocyanin accumulation, was expected to offer protection to photo-inhibitory damage as a consequence of P-limited photosynthesis in the review by Vance et al. (2003). However, the precise role of anthocyanin accumulation under $\mathrm{P}$ limitation stress in plants is as yet unclear. For example, Henry et al. (2012) could not find consistent effects of anthocyanin accumulation in terms of improved photosynthesis or biomass production under $P$ stress in maize and coleus. Furthermore, low $\mathrm{P}$ induces quick increases in potentially damaging reactive oxygen species (ROS) and higher ROS scavenging enzyme activities (Wan et al. 2010), similarly to other abiotic and biotic stresses in plants.

Hormone and signalling pathways are important integrators of stress responses in plants and their role in $\mathrm{P}$ responsiveness is summarized amongst others by Chiou and Lin (2011). Auxin and ethylene signalling is obviously associated with lateral root initiation, which is a pivotal response to low $\mathrm{P}$ as described in the previous section on plant architecture. Gibberellin counteracts auxin effects on lateral root formation. Cytokinin production is repressed at low $\mathrm{P}$ and cytokinin is known to inhibit $\mathrm{P}$ starvation-induced (PSI) genes. Low cytokinin also promotes root growth and the decline in export from roots leads to inhibition of shoot growth even when vacuolar P pools are not depleted. Veneklaas et al. (2012) hypothesize that PUE could be improved by adapting such signalling events to make more effective use of the shoot's P pool as for instance uncoupling of $\mathrm{P}$ deficiency and shoot growth could be attained with manipulating $\mathrm{PHOl}$ gene expression in Arabidopsis. ABA is a major stress hormone, but it has not been shown to have clear effects in $\mathrm{P}$ responsiveness. The more recently identified strigolactones were shown to affect root architecture and to move up from roots decreasing shoot branching in interaction with auxin in response to $\mathrm{P}$ stress (Kohlen et al. 2011). Strigolactones also promote mycorrhizal branching (cf. Ruyter-Spira and Bouwmeester 2012, see further section about mycorrhiza below).

Sugar signalling also interacts with $\mathrm{P}$ responsiveness. Decreased photosynthesis in response to low $\mathrm{P}$ leads to increased starch formation in shoots (Hammond and White 2011). In addition, sugar loading into the phloem is increased and thus allocated to roots, in turn increasing the root/shoot ratio and leading to activation of P-responsive genes (Hammond and White 2011). Even P itself likely works as a direct signal since the non-metabolizable Pi analog phosphite (Phi) also acts as a signal in $\mathrm{P}$ regulation in plants (Chiou and Lin 2011). The inositol phosphate IP3/diacylglycerol (DAG) pathway, working through 
phospholipase $\mathrm{C}$ (PLC) and subsequent $\mathrm{Ca}^{2+}$ signalling, is an important pathway in stress signalling. It is likely involved in P responsiveness, but there is still little known about this (Chiou and Lin 2011).

Many of these physiological responses are complex and difficult to assess for breeding purposes. Yet, some are relatively straightforward, such as the analysis of exudates in response to low $\mathrm{P}$. The more complex traits have been targeted by genomics techniques, such as transcriptomics and metabolomics, which will be discussed in the following section on screening/testing methods.

\section{Phenotyping: efficiently assessing plants for genotypic variation of PUE}

For successful breeding of P-efficient crops, highthroughput selection of optimal genotypes is needed. This will only be feasible when traits involved in PUE are identified that can be scored efficiently. Though field trials are the final judge of the superiority of new varieties, these trials are hampered by variability in environmental conditions, which can mask the genetic variation sought for. More controlled growing conditions will reduce this environmental variation and also enables to impose conditions that more clearly reveal PUE-related traits in the plants tested. Preferably, plants should also be grown in a manner that enables easy assessing of the traits. In the following sections, cultivation methods aimed at testing PUE traits are discussed, first the soil-based systems, followed by the water-based systems. Methods of trait assessment on plants are subsequently presented.

\section{Screening/cultivation methods}

\section{Soil (solid)-based systems}

Various methods have been developed that are targeted specifically to screening for PUE of plants and to dissect these traits into genetic components. The simplest experimental set-up is the use of pots in greenhouses watered by nutrient solutions with various levels of phosphate. In order to improve the representativeness of the pot medium for normal soil conditions, a reproducible slow release/diffusion-limited solid phase system was developed by Da Silva and Gabelman (1992), which is based on adding phosphate pre-absorbed to activated alumina to pure quartz sand (Coltman et al. 1982).

For improved monitoring of root-architectural characteristics, various refinements to container-based cultivation methods were implemented. Ao et al. (2010) described a mini-rhizotron consisting of silicon sand, through which Plexiglass access tubes were placed at $30 \mathrm{~cm}$ distance of each other and at a $30^{\circ}$ angle to the soil surface. Root traits could then be recorded by moving an endoscope camera through the access tubes. Nagel et al. (2012) developed a robotic rhizotron system enabling automatic imaging of both roots and shoots, with a throughput rate of 60 rhizotrons per hour. Fang et al. (2009) managed to record the total root system in situ by combining a transparent root growth medium based on phytagel with 3D laser scanning.

Other refinements were aimed at the observation of specific types of traits, such as distribution of lateral roots and exudations from the roots into the (soil) medium. An example of this is the system of Liao et al. (2004, 2006), that uses containers divided into several compartments by Plexiglas perpendicular to the direction of taproot growth. This enables assessment of root characteristics across several soil layers (e.g. $0-1.5 \mathrm{~cm}, 1.5-6 \mathrm{~cm},>6 \mathrm{~cm}$ ) varying in P levels and availability due to $\mathrm{Al}$ binding. As discussed in the section on external PUE above, under field conditions, the upper soil layer is often the richest in P. Another example is the rhizosphere study container technique (RSC) of Zoysa et al. (1997, 1999) consisting of 2 or 3 soil compartments separated by a $24 \mu \mathrm{m}$ pore-diameter polyester mesh that retained the roots as a planar mat. At harvesting time, soils from each compartment can be sliced using freezing by liquid N2 (Kuchenbuch and Jungk 1982). The slices from the compartment with the plant can be used to measure the root surface area, in particular the mat at the polyester mesh. The slices from the other compartment(s) can be used to measure $\mathrm{P}$ depletion or effects from root exudation in relation to the distance from the root planar mat.

\section{Hydroponics: growing plants on water solutions}

In hydroponics, plants are grown on a liquid medium, enabling controlled supply of nutrients directly to the roots and simple harvesting of the roots. Many studies were using relatively simple hydroponics systems based on aerated nutrient solutions with various levels 
of phosphate with renewal of the solutions at fixed intervals (e.g. Gong et al. 2011; Byrne et al. 2011: perennial ryegrass, Beebe et al. 2006: common bean). An example of an experiment using two levels of phosphate with onion is shown in Fig. 1. One of the simple variants is the nutrient film technique (NFT, used in Hammond et al. 2011): this system uses a shallow stream of water with nutrients running through a gully; the plants are positioned in holes in the upper side and have their root mats in the stream partly exposed to air for optimizing oxygenation. As with the solid phase systems of the previous section, some studies used water-insoluble phosphate forms that should make the system more similar to the situation in the soil. This included the activated alumina system as described in the previous section (Yan et al. 2004: common bean) or variants such as $\mathrm{Ca}-\mathrm{P}, \mathrm{Al}-\mathrm{P}, \mathrm{Fe}-\mathrm{P}$, or phytate-P (Du et al. 2009) or Phosphal (Erro et al. 2010: chickpea, lupin, maize). Liu et al. (2006) showed that such a P-binding system was overcoming a limitation of hydroponics, that is, the poor root hair development that is important to $\mathrm{P}$ uptake in soils (see section on plant architecture above). In their system, which is simply based on TCP (tricalcium phosphate), several crop species, including the usually poorly inducible maize, abundantly grew root hairs, with the only exception of onion, which normally is a poor root hair developer. For combining PUE studies with nodulation by nitrogenfixing Rhizobium in common bean, L'taief et al. (2012) applied hydro-aeroponics. In this system, roots are hanging in a mist of nutrient solution, which improves access of roots to oxygen and nitrogen from the air.

A more sophisticated hydroponics method is based on the Ingestad concept of supplying the nutrient under study in accordance with a crop-specific growth model thus keeping the extent of nutrient limitation as much as possible at a constant level throughout the various growth stages of a seedling. Most of the literature on hydroponics according to the Ingestad concept is addressing nitrogen $(\mathrm{N})$ limitation (Ingestad and Lund 1986; Ingestad and Ågren 1995; Hellgren and Ingestad 1996). Ericsson and Ingestad (1988) showed that hydroponics experiments with phosphorus (P) limitation can be performed similarly to the ones they performed using $\mathrm{N}$ limitation with birch seedlings. In the Ingestad concept the variation in PUE is more likely to be based on variation in internal PUE than in external PUE, as the scavenging capacity of the roots will hardly contribute to PUE, and the root architectural traits will have a different impact (most likely less) on plant growth at varying $\mathrm{P}$ availability in hydroponics than in soil.

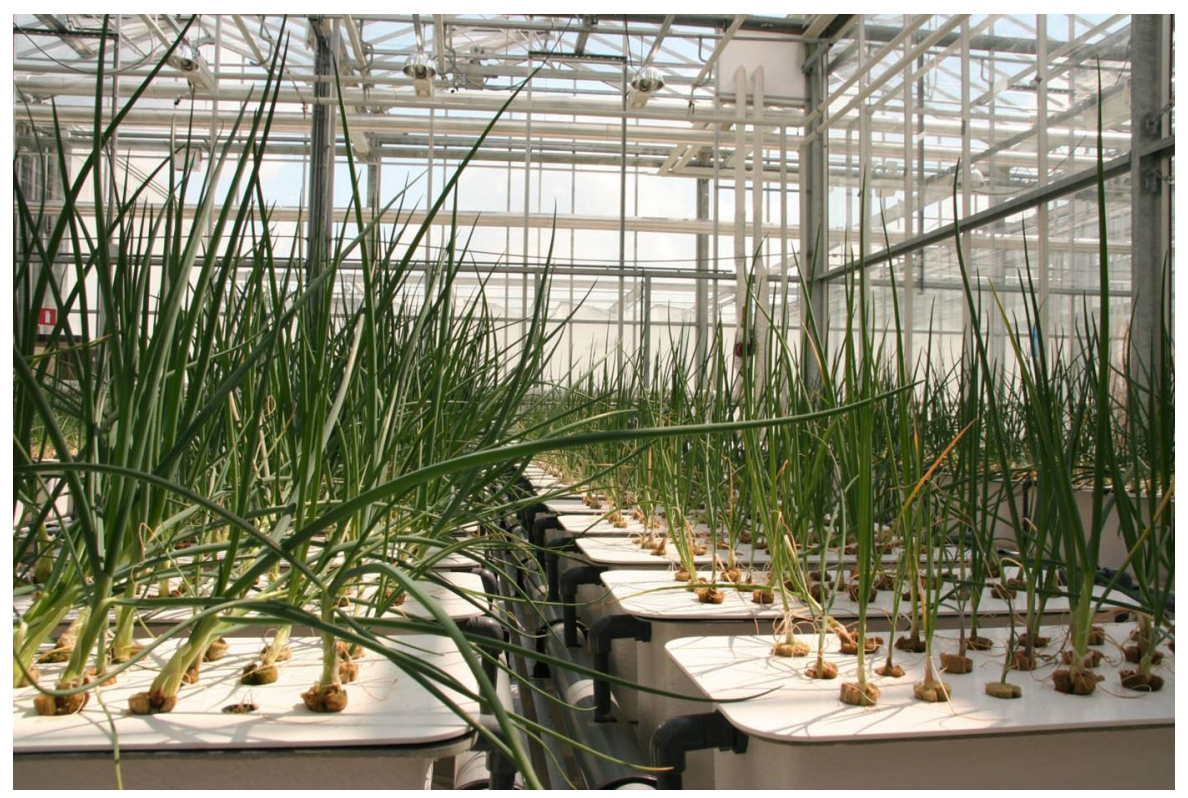

Fig. 1 Hydroponics experiment with onion. In the left-hand row, a nutrient solution containing $40 \mu \mathrm{M}$ P-PO $\mathrm{PO}_{4}$ is used, in the right-hand row, $4 \mu \mathrm{M} \mathrm{P}-\mathrm{PO}_{4}$ (photograph courtesy of Karin Burger) 
Screening/testing methods

In order to compare PUE of plants, many studies performed a number of basic measurements that are relatively efficiently scorable on large numbers of genotypes, usually at seedling/young plant stages. As a rough measure of plant architecture, shoot and root fresh and dry weight, and tiller number in the case of grasses and cereals (Gramineae/Poaceae), were mostly determined. By including measurements of phosphorus levels in the plants, the two basic ways of plant $\mathrm{P}$ efficiency, external and internal PUE, could also be distinguished. For the external PUE, that is, uptake efficiency, the amount of $\mathrm{P}$ taken up by the plant is calculated as $\mathrm{mg}$ phosphorus per plant. This does however not include effects on biomass production per plant. Trolove et al. (1996) more specifically assessed amount of $\mathrm{P}$ taken up per unit root length. Internal PUE addresses metabolic efficiency and is calculated as the ratio of plant biomass produced per unit P: e.g. shoot dry weight (SDW) per mg phosphorus taken up (Trolove et al. 1996; Zoysa et al. 1997, 1999; Zhang et al. 2009). Internal PUE may be difficult to disentangle from external PUE as higher tissue $\mathrm{P}$ may lead to lower PUE; so, some way of correcting for this or equalizing $\mathrm{P}$ acquisition should be employed (Veneklaas et al. 2012). Further refinements were provided by Su et al. (2006) who used SDW/SPU (shoot P uptake) for internal P efficiency in wheat DH lines and Hammond et al. (2009) who evaluated shoot mass/unit $\mathrm{P}$ uptake variation in accessions and varieties of Brassica oleracea.

Roots are notoriously difficult to study due to their subterranean nature. Nevertheless, more and more, systems are developed and refined for monitoring root development and responses to the environment. To obtain more detailed information on root architecture, visual inspection or image analysis was applied on roots from hydroponics (e.g. Yan et al. 2004) or roots cleaned from soil (e.g. Liang et al. 2010). In the latter case, there will always be some level of damage to the finer structures, but efficient methods have been developed even for field trials, such as "shovelomics": excavating a $40 \mathrm{~cm}$ diameter $/ 25 \mathrm{~cm}$ depth soil cylinder at the plant base using a standard shovel, followed by brief shaking off soil, soaking in mild detergent and finally rinsing at low water pressure, all in all taking maximally 10 min for visually root scoring (Trachsel et al. 2011, for maize and bean). This will not work well in heavy clay soils.

A basic laboratory method for observing root morphology is the 2D agar-based system for Arabidopsis using vertically placed petri dishes with the upper segment of agar removed to keep the shoot part free from the agar surface (Dubrovsky and Forde 2012). PUE-related parameters to be assessed involve lateral root density (primordia and roots/primary root or branching zone length), preferably over a period of time encompassing several stages of seedling development. Shi et al. (2013) performed high-throughput assessments of primary and lateral root lengths, and lateral root density using high-throughput imaging of Brassica napus seedling root systems in flat agar trays and ImageJ software (Abràmoff et al. 2004). Wang et al. (2004) zoomed in on root hair traits, using WinRhizo image analysis software (Regent Instruments Inc., Canada) on images of $1 \mathrm{~mm}$ lateral root parts captured by a digital camera on a stereomicroscope. At an even more detailed level, Burton et al. (2012) developed software for high-throughput image analysis of root transections showing an example of roots of common bean and rice grown under low and high phosphorus using the sand/phosphorus-doped alumina system as Da Silva and Gabelman (1992) described in the section on screening/cultivation methods above. Parameters important to PUE at low carbon cost, such as the amount of aerenchyma and the stele diameter (see section on plant architecture above), could be quantified in this way.

As described in the section on screening/cultivation methods above, Fang et al. (2009) assessed root architecture in situ with a 3D laser scanning system achieving a precision of $0.1 \mathrm{~mm}$ with rice and soybean seedlings. For small plant species, such as Arabidopsis, this would be too low resolution. In addition, the scanning size was limited so that no larger and/or mature plants could be observed. A similar system was used by Ingram et al. (2012) to assess root traits in the grass Brachypodium distachyon. In this case, roots were growing in borosilicate cylinders containing Gelzan gum nutrient medium, and root images were captured every $18^{\circ}$ around the whole circumference of the growth cylinder. In normal soils, X-ray computed tomography (CT) was tested but shows problems in overlapping values hampering distinction of roots from soil material. This has recently been tackled by a system of micro-computed tomography using visual 
tracking, called RooTrak. The usefulness of RooTrak was shown in maize, wheat and tomato in various soil textures (Mairhofer et al. 2012).

Effects of roots on the external environment were monitored using hydroponics or the compartmented RSC system described in the section on soil-based screening systems above: $\mathrm{H}^{+}$exudation, organic acid exudation or acid phosphatase exudation. For instance, Yan et al. (2010) found a higher level of acidification with the more $\mathrm{P}$ efficient plants of wheat in an RSC system. They did not find differences in the levels of acid phosphatases exuded.

Internal PUE is difficult to assess focussing on high-throughput, easily scorable phenotypic traits. An indication for mobilization efficiency may come from the observation by Ozturk et al. (2005) that wheat genotypes with relatively strong senescence symptoms in older leaves were producing higher biomass under $\mathrm{P}$ stress; these genotypes may have been mobilizing $\mathrm{P}$ more quickly from the older leaves. Akhtar et al. (2008) studied internal PUE on a number of Brassica cultivars by following the distribution of $\mathrm{Pi}$ and Po (organically bound P) among plant parts after $\mathrm{P}$ deprivation in hydroponics. They showed an association of higher biomass production with large $\mathrm{Pi}$ reserves at high $\mathrm{P}$ availability and fast $\mathrm{Pi}$ internal remobilization at low $\mathrm{P}$ to sustain $\mathrm{Po}$ homeostasis; at $\mathrm{P}$ stress, roots and young leaves were the most important sinks for Pi. A relatively efficiently scorable physiological parameter is leaf chlorophyll content, which is affected by $P$ stress and can be measured in vivo using a SPAD meter (e.g. Wan et al. 2010; Cai et al. 2012). Furthermore, metabolites can be measured in plant samples using e.g. GC-MS (Byrne et al. 2011) and ions using e.g. HPLC (Uwimana et al. 2012). A more sophisticated technique was the imaging of ionic movements in plants using real-time radioisotope imaging systems (in this case ${ }^{32} \mathrm{P}$ ) by Kanno et al. 2012, which however appears to be too complex for efficient screening. Recently, a system using NMR or positron emission tomography provided very useful information, but would be even more difficult to apply in practice (De Smet et al. 2012). Another promising development is in vivo phosphate tracking by fluorescent reporter proteins (Gu et al. 2006; Sun et al. 2008; review: Frommer et al. 2009), but this will also not be easily implemented in a high-throughput screening system.
Changes in gene expression in order to adapt to $\mathrm{P}$ starvation can also be indicative for strategies and traits that contribute to PUE. Whole transcriptome expression studies with micro-arrays have been used to discover genes that are responsive to changes in $\mathrm{P}$ in Arabidopsis, tomato, bean, maize, rice and wild mustard (Nilsson et al. 2010) and potato (Hammond et al. 2011). The next chapter will further elaborate on P-responsive genes.

\section{Genetics and breeding for PUE}

PUE shows large variation between species (Föhse et al. 1988, 1991). For instance, barley is generally less $\mathrm{P}$ efficient than maize and rice. Most importantly, it also shows considerable genetic variation within species (e.g. Ozturk et al. 2005; Hammond et al. 2009), which is the basis for further improvement by breeding. However, breeding for PUE is likely to be a complicated process due to the complexity of this trait and the influence of the environment. For instance, selection in alfalfa for plants with high $\mathrm{P}$ levels on P-deficient alkaline soil showed only little progress per selection cycle, but in this outcrossing crop species, this was confounded with inbreeding effects (Sain et al. 1994). Górny and Sodkiewicz (2001) used diallel hybrids from 5 or 6 barley inbreds that were evaluated at maturity and found mainly additive genetic effects for PUE, even more so than at the vegetative stage. In addition, narrow-sense heritabilities were relatively low under stress conditions. Furthermore, testing for $\mathrm{P}$ use efficiency in the field can be problematic because of the often large spatial heterogeneity of $\mathrm{P}$ availability in the soil. In studies on white clover, $\mathrm{P}$ use efficiency was found to be heritable under glasshouse conditions, but this turned out not to be the case under field conditions (Caradus and Dunn 2000). On the other hand, successful selection for increased PUE was reported more recently for new soybean varieties, in this case by focussing on root architecture. In southern China, the new varieties outperformed existing varieties on acidic soils, which have low availability of $\mathrm{P}$ for plants (Wang et al. 2010). Similar success was reported for common bean for Africa, Asia and South America (Lynch 2007).

Classical breeding research has been greatly enhanced by recent developments in molecular 
techniques, such as marker-assisted selection (MAS) and genomics. This enables to also dissect complex quantitative traits into underlying genetic factors that can be localized on the genome, i.e. by utilizing genetic linkage maps based on DNA markers and statistically locating sites on these maps linked to desirable traits, quantitative trait loci (QTL). In the following section, QTLs reported for PUE will be discussed.

\section{Genetic factors: QTLs}

For many of the PUE traits discussed earlier, QTLs have been reported in different crops. Many of the genetic studies on PUE address highly quantitative traits, such as SDW and tiller number (TN) in wheat (Su et al. 2006), grain yields in maize (Cai et al. 2012) and SDW, R(oot)DW and biomass/yield in soybean (Liang et al. 2010, Zhang et al. 2009). Also, P contents were determined (Yan et al. 2004, for root and shoot separately, Liang et al. 2010). Furthermore, approximations of $\mathrm{P}$ uptake efficiency, such as shoot $\mathrm{P}$ uptake (SPU) as SDW $\times$ total $\mathrm{P}$ concentration (Su et al. 2006) or $\mathrm{P}$ acquisition efficiency as total $\mathrm{P}(\mathrm{mg}) / \mathrm{plant}$ ) (Zhang et al. (2009) were calculated; likewise for internal PUE g dry weight/mg phosphorus taken up, was calculated by Zhang et al. (2009). Using 152 RILs from a soybean cross, Zhang et al. (2009) detected a total of 34 QTLs for PUE-related biomass traits including a QTL cluster that accounted for $74 \%$ of the phenotypic variation and that was coinciding with previously found QTLs for P and N efficiency. They also found a QTL cluster associated with increased acid phosphatase activity. In addition, 8 pairs of epistatic QTLs were identified on 12 linkage groups. In a later report, they added 13 QTLs related to grain yield under P stress: flower and pod abscission rates (FAR and PAR, respectively) (Zhang et al. 2010). Among them was a major QTL for FAR explaining $32 \%$ of phenotypic variation that co-localized with QTLs for PAR, and there were several QTLs colocalizing with QTLs for vegetative traits under low P found in earlier studies.

Root architectural traits, such as specific root lengths in common bean (Beebe et al. 2006) and lateral root length and density in maize (Zhu et al. 2005) and Brassica napus (Shi et al. 2013) were also analysed for QTLs under various P levels. Shi et al. (2013) detected 38 QTLs on 9 of the 19 chromosomes, including a cluster of highly significant biomass and lateral root number and root density QTLs on chromosome A03. This cluster co-localized with comparable traits on syntenic regions of the B. oleracea and Arabidopsis genome. At a more detailed level, root hair density and length were also analysed. In field trials on low P soil with 88 RILs from a soybean cross, Wang et al. (2004) showed root hair density to have a lower heritability than average root hair lengths. With 86 RILs from a common bean cross, Yan et al. (2004) also found relatively low heritabilities for root hair traits in hydroponics, except for some acid exudation characteristics. Nevertheless, they found 8 QTLs for root hair traits (density and length) and 9 QTLs for acid exudation characteristics. Three of these acid exudation QTLs co-localized with two P uptake efficiency QTLs identified in a field experiment at low P. For convenience, many studies used seedlings/ young plants, but there are also examples on mature plants assessing root hair traits, and flower and pod abscission in response to $\mathrm{P}$ stress in soybean (Wang et al. 2004; Zhang et al. 2010).

QTLs for root exudates were reported by Yan et al. (2004) [acid $\left(\mathrm{H}^{+}\right)$exudation] and Cálderon-Vázquez et al. (Calderón-Vázquez et al. 2011). QTLs for leaf area and chlorophyll content in maize at the silking stage were assessed by Cai et al. (2012). They identified QTLs for both leaf area and grain yield under low P and a major QTL affecting chlorophyll content under low $\mathrm{P}$ in a genomic region at which QTLs controlling chlorophyll levels at an early growth stage had been reported before. Internal P efficiency traits clearly are more difficult to assess. Internal PUE is often inferred from general plant measurements and P contents. Using 73 wheat lines, Ozturk et al. (2005) showed PUE (ratio of shoot biomass development under low to that under adequate $\mathrm{P}$ supply) to be correlated with total shoot $\mathrm{P}$ content rather than with $\mathrm{P}$ concentration of shoots. Similarly, Sain et al. (1994) showed little success in selecting for PUE based on higher $\mathrm{P}$ concentrations in alfalfa plants grown on alkaline soils. These observations indicate that increased $\mathrm{P}$ uptake does not necessarily lead to more internal P-use-efficient genotypes. For highly P-efficient genotypes having low $\mathrm{P}$ concentrations, it could be concluded that they have an efficient use of $\mathrm{P}$ for biomass production.

QTLs for PUE could be put to use through introgression into elite varieties, although as yet this 
has hardly been done in breeding programmes (Vinod and Heuer 2012). The QTLs could also be used to identify genes involved in PUE through map-based cloning, although still few QTLs have led to identification of underlying genes. QTLs for primary root length in B. napus co-localized with an Arabidopsis syntenic region (Block E) containing the $L P R 2$ gene involved in arresting primary root growth in response to low $\mathrm{P}$ and the $P R D$ gene involved in primary and lateral root elongation (Shi et al. 2013). A recent example of a gene experimentally shown to be involved in PUE is PSTOLI encoding a protein kinase in rice that was originally tracked through a major QTL, Sus1, from a traditional variety (Gamuyao et al. 2012). Another interesting example in soybean is a QTL found both in a genome-wide association study (GWAS) and through linkage mapping, which led to the identification of a candidate gene encoding an acid phosphatase, $G m A C P 1$, that was subsequently shown to be involved in PUE (Zhang et al. 2014). Genes related to PUE can also be traced using alternative methods, such as mutagenesis and gene expression microarrays.

\section{Genes related to PUE}

Using subtractive cDNA libraries (e.g. Tian et al. 2008); microarrays (e.g. Wang et al. 2002) and mutants in phosphorus utilization, a broad array of genes was identified that are responsive to $\mathrm{P}$ stress. Recent overviews related genes involved in PUE mostly found in Arabidopsis to homologues in crop species such as tomato, rice, and maize (CalderónVázquez et al. 2011; López-Arredondo et al. 2014).

PUE-related genes include transcription factors, genes involved in signal transduction, hormone-responsive factors, metabolic factors (e.g. phosphatases) and proteins directly involved in $\mathrm{P}$ scavenging (e.g. acid phosphatases and high-affinity $\mathrm{P}$ transporters).

A gene that may act as a central regulator of the response to low P is PHR1/PHL1 (Chiou and Lin 2011; López-Arredondo et al. 2014). This gene encodes an R2R3 MYB-CC transcription factor that binds to a P1BS element in Pi-responsive gene promoters in Arabidopsis. Orthologues of this gene were identified in rice and common bean. It has an effect on a wide array of traits: root architecture, $\mathrm{P}$ transport/allocation, anthocyanin production, and starch accumulation. Interestingly, PHR1 is involved in regulation of
miR399, a microRNA acting as a shoot-derived longdistance signal towards roots, where it targets $\mathrm{PHO} 2$. Repression of expression of $\mathrm{PHO} 2$ in turn leads to $\mathrm{P}$ starvation responses, such as expression of highaffinity transporters. High affinity transporters encoded by the Pht 1 gene family in Arabidopsis, such as PHT1;1 and PHT1;4 (Chiou and Lin 2011), are mainly responsible for $\mathrm{P}$ uptake in the rhizosphere; this family is also represented in crop plants. Thus, under low $\mathrm{P}$ conditions, 14 members are induced in soybean, 5 in maize and 4 out of a total of 13 in rice (LópezArredondo et al. 2014). Phtl genes are also expressed in other parts of the plant and so will be involved in remobilization of $\mathrm{P}$ within the plant. For instance, AtPT2 (PHT1;4), was shown to be induced in flowers and senescing leaves under $\mathrm{P}$ deficiency conditions in Arabidopsis by promoter-driven reporter gene studies (Karthikeyan et al. 2002). Some Phtl genes are specifically induced in mycorrhiza (see below section "Breeding for PUE related to interactions with microorganisms"). An overview of genes related to PUE is given in Supplementary Table 1.

Genes identified as related to PUE can be further functionally characterized by transforming them into other plant (species) or changing their expression in transgenic plants. In this way, valuable insights can also be gained for selection and/or marker development for classical breeding (e.g. Tian et al. 2012). An aluminium resistance gene ALMT1 from wheat was shown to confer improved $\mathrm{P}$ uptake when expressed in barley (Delhaize et al. 2009), and an Arabidopsis AVP1 $\mathrm{H}^{+}$-PPase increased salt/drought tolerance of tomato and rice by promoting $\mathrm{Na}^{+}$sequestration in the vacuole and osmoregulation (Gaxiola et al. 2011, 2012). The transgenic expression of AVP1 $\mathrm{H}^{+}$-PPase also resulted in a larger root system, leading to improved plant performance under low $\mathrm{P}$, including higher shoot and fruit yield.

Transgenic plants may also be directly useful for cultivar development when they perform well under agronomic conditions at low $\mathrm{P}$ availability and preferably also under conditions without $\mathrm{P}$ stress. These conditions may not always be met as PUE, like other abiotic stress-related traits, is complex and single gene effects may well be accompanied with trade-offs, particularly under situations of high $\mathrm{P}$ availability. For instance with the transgenic introduction of the $D R E B 1 A$ gene that confers drought and cold tolerance, it was necessary to put it under the regulation of a stress- 
inducible promoter to avoid negative effects on yield under normal growing conditions (Kasuga et al. 2004). Pyramiding of several genes that contribute to PUE may lead to further improvement, but balancing expression levels for optimal effect may not be straightforward. As yet, no GM PUE crop variants have been reported to be in a commercial pipeline. A few examples of interesting transgenic approaches to improving PUE have been reported. López-Arredondo and Herrera-Estrella (2012) enabled Arabidopsis and tobacco to metabolize phosphite $\left(\mathrm{PO}_{3}{ }^{3-}\right)$ by transforming them with a phosphitespecific oxidoreductase $p t x D$ gene from Pseudomonas stutzeri WM88. As plants normally are not able to use phosphite for their $\mathrm{P}$ supply, this would enable this transgenic crop to outcompete weeds under phosphite fertilization. Phosphite could be administered as foliar fertilizer to prevent enrichment of soils for phosphitemetabolizing microorganisms, which could provide $\mathrm{P}$ in a plant-metabolizable form. At the same time, phosphite is reported to be helpful in controlling some pathogens, particularly oomycetes. The possibilities of using phosphite as an organic agent against pathogens has been reviewed by Bus et al. (2011). Another interesting transgenic plant improved for utilization of an inaccessible P source was cotton expressing a phytase gene from Aspergillus ficuum with the root-specific promoter pyk10 from Arabidopsis myrosinase and an extracellular signal peptide from carrot (Liu et al. 2011). This enabled the plant to excrete phytase from its root system and thus to utilize a significant part of the organic $P$ in the soil which is present as phytate (=myo-inositol hexakisphosphate, amounting to 4-20, sometimes up to $40 \%$ of $\mathrm{P}_{\mathrm{o}}$ in soils). Phytate strongly adsorbs to soil particles, precipitates with $\mathrm{Fe} / \mathrm{Al}$ in acid soils and with $\mathrm{Ca}$ in alkaline soils. Therefore, it is not easily accessible to plants. In the field, it most likely is released by microorganisms (Richardson et al. 2011). Nevertheless, a soybean provided with an Arabidopsis PAP15 acid phosphatase (APase) coupled to an extracellular signal peptide from carrot showed enhanced exudation activity leading to a higher yield on low- $\mathrm{P}_{\mathrm{i}}$ acid soil or a sand/phytate mixture (Wang et al. 2010).

\section{Breeding for PUE related to interactions with microorganisms}

The previous section already indicated the importance of soil-based microorganisms in the mobilisation of tightly bound $\mathrm{P}$ in the soil, such as phytate, making it available to plants (cf. Richardson et al. 2011; Bulgarelli et al. 2013). These microorganisms may be more or less associated with the rhizosphere; some show a more intimate relationship with the plant and are referred to as endophytes. An example of a fungal root-associated endophyte is the basidiomycete Piriformospora indica that appears to enhance $\mathrm{P}$ uptake of plants (Franken 2012). Also endophytes occurring in shoots, such as the much studied clavicipitaceous fungus Neotyphodium in grasses, may impact nutrient use efficiency, including uptake in the roots, e.g. by promoting the production of exudates ( $\mathrm{Li}$ et al. 2012; Omacini et al. 2012; McNear and McCulley 2012). It is not yet clear whether there is a direct effect of these endophytes on nutrient status and reports in literature are sometimes contradictory (Franken 2012; Omacini et al. 2012; McNear and McCulley 2012). The Neotyphodium endophyte has been shown to negatively interact with arbuscular mycorrhizal fungi that have a significant role in plant $\mathrm{P}$ nutrition (see further below) (Mack and Rudgers 2008; McNear and McCulley 2012), although there are exceptions to this (Omacini et al. 2012). Although the potential of using $P$ status-enhancing microorganisms for plant growth improvement was reviewed (Richardson et al. 2011; Bulgarelli et al. 2013), little has been published yet about improvement of plant nutrient efficiency by selecting for optimal genotype combinations of plant and rhizosphere microorganisms or endophytes, except for the arbuscular mycorrhizal (AM) fungi.

The mycorrhizal root interaction with AM fungi can improve $\mathrm{P}$ uptake capacity of plants as the fungal hyphae can greatly increase the volume of soil scavenged for $\mathrm{P}$, particularly for species with poor root and root hair development, such as onion (see plant architecture section above). The $\mathrm{P}$ absorbed by the fungal hyphae is relatively quickly transported to the root cortical cells. The fungus obtains carbon from the plant, which in principle makes this a mutualistic interaction (symbiosis). The majority of plant species are capable of developing mycorrhizae with AM fungi, but members of the Brassicaceae and Chenopodiaceae (including crop species, such as Brassicas and beet) do not form mycorrhizae. Also specialists forming the so-called cluster roots such as lupin (see section on plant 
architecture above) often lack mycorrhizae. Low soil $\mathrm{P}$ availability and low management intensity (e.g. organic as compared to conventional cultivation) tend to lead to higher diversity of mycorrhizal communities (Verbruggen et al. 2012). This needs not always be the case. For instance, Galván et al. (2009) did not find consistent differences in mycorrhizal diversity between organic and conventional cultivations of onion.

The balance between plants and fungi in mycorrhizae is complex and there is large variation in performance between specific combinations of plant and fungal genotypes, including examples where plant growth is apparently hampered under mycorrhizal colonization (Smith and Smith 2011; under experimental conditions of high $\mathrm{P}$ in Kaeppler et al. 2000). This can be related to the amount of $P$ gained for the amount of $\mathrm{C}$ provided, but there may also be other more specific effects, such as the suppression of direct P uptake (DP) through the root(hair)s even at a low level of mycorrhization (and poor functioning of mycorrhizal pathway, MP, i.e. P uptake through the fungal hyphae) (Smith et al. 2011, 2012). Ecological functionality of mycorrhiza might also lie in increasing the plant's competitiveness without gains in shoot growth compared to a situation without AM fungus (Smith and Smith 2011).

In breeding crops for PUE, plant fungal combinations should show significant gains in yield performance relative to the non-mycorrhizal state for the breeders' elite plant genotypes in actual field situations. An extreme example of yield gains from mycorrhiza that are not directly agronomically useful is the maize mutant $l r t 1$, which is deficient in lateral root formation and shows a very poor PUE. This could be largely corrected by mycorrhiza, so the mutant clearly showed a high responsiveness to mycorrhiza, but as such it would not be a good basis for cultivar development (Sawers et al. 2008). It could be useful however to help in dissecting plant traits relevant for mycorrhizal responsiveness in such a manner that these traits could subsequently be successfully introgressed into the best performing plant lines in terms of yield. This could be a valuable research approach in view of the complex genotype $\mathrm{x}$ environment interactions discussed above. This is further elaborated in the following section on phenotyping and selection.
Phenotyping

As with phenotyping of PUE described in the section on screening/testing above, growth gains as a consequence of mycorrhization (mycorrhizal responsiveness) were assessed by measuring SDWs on a series of genotypes (Hetrick et al. 1996). In view of the complex interactions between plant and fungal genotypes mentioned above, it may be difficult to disentangle responsiveness to AM fungi from other traits contributing to the plant's performance under nonmycorrhizal (NM) conditions, i.e. to assess variation positively linked to the symbiosis without sacrificing on yield performance already achievable under NM, and thus useful to breeding for mycorrhizal traits. As mycorrhizal responsiveness varies with $\mathrm{P}$ availability, its characteristics may only be well assessed by extracting parameters, such as (absolute) responsiveness, from a response curve based on plant growth at a range of $\mathrm{P}$ concentrations. In this way, Janos (2007) made a distinction between the plant's dependence (i.e. the lowest $\mathrm{P}$ availability at which NM plants can grow) and the plant's responsiveness (i.e. the growth difference with NM plants or the fungal effectiveness). However, for efficient screening of a breeding population this would be too labour-intensive. Sawers et al. (2010) expected Janos's responsiveness to be of higher value to improving cultivated plants' performance in terms of yield than his dependence as the latter may mostly represent the extent to which plants with basically poor PUE can be compensated by mycorrhiza (see the extreme example of the maize mutant lrtl in the previous section). Thus, Sawers et al. (2010) developed linear models to separate these two types of variation, more specifically variation in common between $\mathrm{M}$ and $\mathrm{NM}$ (or NC, non-colonized) plants and variation specific to either the NM or M state. They used data on wheat from Hetrick et al. (1992) and maize from their own and Kaeppler et al. (2000). Little mycorrhiza-specific variation was found in the wheat dataset, whereas more outliers expected to be specifically related to mycorrhizal plant performance, both positive and negative, were found amongst the maize lines. In the latter case, a maize line that responded negatively to mycorrhiza was identified that in subsequent tests showed little responsiveness across a wide range of $\mathrm{P}$ availability, whereas a positive maize line showed a shift to increased performance more specifically related to mycorrhiza under low P (also 
see QTLs below). Dissecting common and mycorrhiza-based genetic variation would appear to be even more problematic with the more AMF-dependent onion, which has a rather weak root system largely lacking root hairs (see section on plant architecture above), so likely a high mycorrhizal dependence. Galván et al. (2011) found relative mycorrhizal responsiveness (i.e. weight difference between mycorrhizal and non-mycorrhizal (NM) plants divided by the weight of NM plants for each plant genotype) to be unsuitable as breeding criterion for onion as it was negatively correlated with NM plant's biomass, in line with Sawers et al. (2010). Instead, Galván et al. (2011) proposed average performance (AP) of mycorrhizal and NM plants as a selection index, as it was positively correlated with biomass of mycorrhizal and NM plants. In addition, they did not find support for a decrease of mycorrhizal responsiveness with modern onion varieties, which could allegedly be a consequence of selection for intensive cultivations where high $\mathrm{P}$ availability may be accompanied by poor mycorrhiza development. However, Galván et al. (2009) had already shown that mycorrhiza is also well developed and contributes to yield under high $\mathrm{P}$ in onion, which might be related to its poorly developed root system. Sawers et al. (2010) showed a decrease in mycorrhizal responsiveness for wheat cultivars when compared to older landraces, as concluded by Hetrick et al. (1992) based on relative responsiveness, to be also unlikely from their own modelling of data of Hetrick et al. (1992) described above. Similar conclusions as to no significant changes in mycorrhizal responsiveness were reached by a meta-analysis on cultivars of a series of annual crop species for the period 1981-2010 by Lehmann et al. (2012).

Testing mycorrhizal responsiveness of plant genotypes is usually performed in pot cultures in the greenhouse. In addition, hydroponics experiments involving mycorrhizal plants were reported (Colpaert and Verstuyft 1999; Oseni et al. 2010), but in these cases, solid substrates, vermiculite or perlite, were used in combination with nutrient solutions analogous to the Ingestad approach described above (Ingestad and Lund 1986). As with PUE of the plants themselves, molecular marker-assisted breeding and genomic methods have been applied to mycorrhizal crop studies. These are discussed in the following sections on QTLs and genes.
Genetic factors: QTLs and genes

Using 197 RILs from a cross between the maize inbreds B73 x Mo17 QTLs were identified, among which 3 for SDW under non-mycorrhizal conditions and low $\mathrm{P}$ and 1 for mycorrhizal responsiveness (Kaeppler et al. 2000). Although the lines greatly differed in relative responsiveness, QTLs appeared to be more based on progeny variation in PUE under nonmycorrhizal conditions than on variation specifically related to mycorrhiza. This was elaborated by modelling in Sawers et al. (2010), who opted for different combinations of lines for studying QTLs focussed on trait variation more specifically related to mycorrhiza than the ones used in Kaeppler et al. (2000) (see previous section). In an Allium cepa x (A. roylei x A. fistulosum) bridge cross, Galván et al. (2011) identified several QTLs for average performance (AP) across experiments in two years. There was a co-localization of QTLs for biomass, AP and mycorrhizal responsiveness at two sites, on chromosomes 2 and 3, respectively, and of QTLs for biomass, AP and the number of roots on linkage group 9 (this latter LG could not be linked to a specific chromosome for lack of suitable markers).

Hetrick et al. (1995) used chromosomal substitution lines in wheat to locate genomic regions associated with mycorrhizal responsiveness. Several chromosomes from a responsive cultivar (Cheyenne) conferred a significant effect of mycorrhiza on dry weight to a non-responsive cultivar (Chinese Spring). Interestingly, one of the chromosomes (5B) coming from another non-responsive cultivar (Hope) also led to a significant mycorrhizal growth response in this nonresponsive cultivar. The apparent complexity of the genetic interactions between chromosomes were also evident from the distribution of mycorrhizal responsiveness among related species having either the wheat A, B or D genome. For instance, some B chromosomes were most effective in conferring mycorrhizal responsiveness, but the species believed to be most similar to the B genome ancestor of wheat, Aegilops speltoides, was not found to be responsive to mycorrhiza.

Specifically induced expression of phosphatases and $\mathrm{P}$ transporters in mycorrhizal plants has been reported, e.g. the high-affinity $\mathrm{P}$ transporter Pht $1 ; 4$ in the leguminous model plant Medicago truncatula and its orthologue in the grass model plant Brachypodium 
distachyon (Hong et al. 2012). Homologues were also reported for the cereal species rice, maize, barley and wheat. In rice, $10 \mathrm{Pht}$ genes were expressed in roots, of which Pht1;2 and Pht1;6 were decreased under nonmycorrhizal compared to mycorrhizal condition, whereas Pht1;11 was induced in the mycorrhizal state (Sawers et al. 2008). This could be related to the apparent repression of the direct phosphate uptake pathway by the mycorrhizal pathway discussed above. An overview of genes reported is in Supplementary Table 1.

\section{Summary and conclusions}

PUE is a complex trait for plant breeding, with many potential interactions and trade-offs with other factors affecting crop yield, such as water use efficiency and energy balance (e.g. Jin et al. 2005). PUE can however be dissected into traits that are more amenable to screening and selection. Among these are physiological traits, such as root exudation of acids and phosphatases enabling scavenging for $\mathrm{P}$ in the soil, and architectural traits primarily of the root. There are reports of successful development of PUE varieties for acid/P-fixing soils in the tropics and subtropics for common bean and soybean, by focussing on root architectural traits (Lynch 2007; Wang et al. 2010). Important aspects of root architecture are the number and morphology of lateral root as well as their localization particularly in the often more P-rich top layers of the soil. In addition, root hair density and length are particularly helpful in absorbing $\mathrm{P}$ from soils.

Roots are notoriously difficult to study because of their subterranean localization. Nevertheless, cultivation methods that allow root phenotyping of germplasm for PUE have been developed, ranging from simple pot cultures to sophisticated hydroponics and systems enabling three-dimensional root evaluation or root activities in various soil compartments (e.g. top vs. deeper layers, or rhizosphere vs. bulk soil). In some of these systems, root architecture can even be observed in situ. Refinements, such as slowly releasing P carriers, have helped to make these systems behave more like soils in the fields, even the hydroponics. Still, in the soil, $\mathrm{P}$ is often highly heterogeneously distributed and therefore, PUE of plants is more difficult to assess and corroborate in the field.
With all these phenotyping systems, sets of genotypes have been assessed for a whole range of crops, such as maize, rice, barley, wheat, common bean, soybean and brassicas. Traits measured include those for root architecture mentioned above, but also shoot traits, such as leaf area, chlorophyll content, and flower and grain development. This has led to identification of genetic factors involved in these traits as QTLs. For instance, QTLs have been found for shoot/root ratio, total $\mathrm{P}$ uptake per plant and internal PUE (biomass per P taken up). Effectiveness of breeding approaches based on such traits and QTLs often still needs to be assessed under the complex and variable conditions in the field, but there are examples of QTLs co-localizing with QTLs for PUE in field trials. Some QTL studies were even performed directly in the field. Genes involved in P responsiveness of plants have also been identified, rarely from QTLs (see PSTOL1 above), more from mutants and microarray studies of gene expression, in several cases corroborated by plant transformation studies. In addition, several potentially interesting examples of direct applications of transgenic plants for improving crop production have been reported, although these still need to prove their value under more variable field conditions. Knowledge of the genes involved in $\mathrm{P}$ responsiveness could also be applied in markerassisted breeding approaches (MAB), allele mining etc., but few reports on that have appeared yet.

There are clear examples of trade-offs with improved PUE, such as carbon costs of large root and/or exudation systems, or a focus on root extension in higher soil levels at the expense of deeper layers for water use efficiency. Nevertheless, plants have been developed with apparently relatively little compromises with respect to other traits, such as PSTOL1 in rice in which enhancement of early root development also led to increased uptake of other nutrients and water. Another example is AVPI in tomato with improved salt/drought tolerance accompanied by a larger root system that also enhanced PUE, and shoot and fruit yields.

Mycorrhizal symbiosis is another important opportunity for improving PUE, particularly the widespread type involving arbuscular mycorrhizal (AM) fungi. The AM fungi (Glomerales) are a difficult group to study, as they are obligatory biotrophs, so they cannot be studied separately from their hosts. Nevertheless, a lot of progress has been made in unravelling the 
interaction between $\mathrm{AM}$ fungi and plants, and the relevance for $\mathrm{P}$ acquisition of the host plant. It has also been proven amenable to the approaches described for identification of traits involved in PUE: phenotyping under more or less controlled conditions, and identification of QTLs and genes involved in mycorrhizal responsiveness. There are also specific complications: it may be difficult to select for elite plant and fungal genotype combinations consistently improving yields across a range of $\mathrm{P}$ levels in the field and to distinguish plant performance specifically due to mycorrhiza from that due to plant traits working without fungal colonization. Several ways of dissecting plant responsiveness to mycorrhiza have been reported. Furthermore, mycorrhizal performance in the field may even be more difficult to assess and predict from experimental work under controlled conditions than basic PUE traits of plants.

In conclusion, breeding for PUE appears to be feasible by dissecting it into traits amenable to genetic analysis and manipulation. For this, it is important to have a phenotyping system optimal for assessing root architectural traits, including $\mathrm{P}$ scavenging using root exudations and mycorrhiza. Apart from this external PUE, it will also be important to develop highthroughput methods to dissect the more difficult accessible internal PUE, as this will likely be more efficient, if only for working around the energyconsuming investments in $\mathrm{P}$ uptake capacity related to external PUE.

Acknowledgments The work described in this study was carried out in the framework of the Research Program on Plant Breeding and Propagation Materials (BO-26.02) funded by the Dutch Ministry of Economic Affairs.

Open Access This article is distributed under the terms of the Creative Commons Attribution 4.0 International License (http:// creativecommons.org/licenses/by/4.0/), which permits unrestricted use, distribution, and reproduction in any medium, provided you give appropriate credit to the original author(s) and the source, provide a link to the Creative Commons license, and indicate if changes were made.

\section{References}

Abràmoff MD, Magalhães PJ, Ram SJ (2004) Image processing with Image J. Biophoton Int 11:36-41

Akhtar MS, Oki Y, Adachi T (2008) Intraspecific variations of phosphorus absorption and remobilization, $\mathrm{P}$ forms, and their internal buffering in Brassica cultivars exposed to a P-stressed environment. J Integr Plant Biol 50:703-716
Ao J, Fu J, Tian J, Yan X, Liao H (2010) Genetic variability for root morph-architecture traits and root growth dynamics as related to phosphorus efficiency in soybean. Funct Plant Biol 37:304-312

Ashley K, Cordell D, Mavinic D (2011) A brief history of phosphorus: from the philosopher's stone to nutrient recovery and reuse. Chemosphere 84:737-746

Beebe SE, Rojas-Pierce M, Yan X, Blair MW, Pedraza F, Muñoz F, Tohme J, Lynch JP (2006) Quantitative trait loci for root architecture traits correlated with phosphorus acquisition in common bean. Crop Sci 46:413-423

Bulgarelli D, Schlaeppi K, Spaepen S, Loren Ver, van Themaat E, Schulze-Lefert P (2013) Structure and functions of the bacterial microbiota of plants. Annu Rev Plant Biol 64:807-838

Burton AL, Williams M, Lynch JP, Brown KM (2012) Rootscan: software for high-throughput analysis of root anatomical traits. Plant Soil 357:189-203

Bus CB, Boeringa R, Schepers HTAM (2011) PK2 as organic pesticide against Phytophthora infestans in potato [Dutch] Report PPO nr. 3250112110. Applied Plant Research, Wageningen UR, Lelystad

Byrne SL, Foito A, Hedley PE, Morris JA, Stewart D, Barth S (2011) Early response mechanisms of perennial ryegrass (Lolium perenne) to phosphorus deficiency. Ann Bot 107:243-254

Cai H, Chu Q, Yuan L, Liu J, Chen X, Chen F, Mi G, Zhang F (2012) Identification of quantitative trait loci for leaf area and chlorophyll content in maize (Zea mays) under low nitrogen and low phosphorus supply. Mol Breed 30:251-266

Calderón-Vázquez C, Sawers RJH, Herrera-Estrella L (2011) Phosphate deprivation in maize: genetics and genomics. Plant Physiol 156:1067-1077

Camacho-Cristóbal JJ, Rexach J, Conéjéro G, Al-Ghazi Y, Nacry P, Doumas P (2008) PRD, an Arabidopsis AINTEGUMENTA-like gene, is involved in root architectural changes in response to phosphate starvation. Planta 228:511-522

Caradus JR, Dunn A (2000) Adaptation to low fertility hill country in New Zealand of white clover lines selected for differences in response to phosphorus. $\mathrm{N} Z \mathrm{~J}$ Agric Res 43:63-69

Chen A, Gu M, Sun S, Zhu L, Hong S, Xu G (2011) Identification of two conserved cis-acting elements, MYCS and $\mathrm{P} 1 \mathrm{BS}$, involved in the regulation of mycorrhiza-activated phosphate transporters in eudicot species. New Phytol 189:1157-1169

Chiou T, Lin SI (2011) Signaling network in sensing phosphate availability in plants. Annu Rev Plant Biol 62:185-206

Colpaert JV, Verstuyft I (1999) The Ingestad concept in ectomycorrhizal research: possibilities and limitations. Physiol Plant 105:233-238

Coltman RR, Gerloff GC, Gabelman WH (1982) A sand culture system for simulating plant responses to phosphorus in soil. J Am Soc Hortic Sci 107:938-942

Cordell D, Drangert JO, White S (2009) The story of phosphorus: global food security and food for thought. Glob Environ Change 19:292-305

Da Silva AE, Gabelman WH (1992) Screening maize inbred lines for tolerance to low-P stress condition. Plant Soil $146: 1-2$ 
De Ridder M, De Jong S, Polchar J, Lingemann S (2012) Risks and opportunities in the global phosphate rock market. Robust strategies in times of uncertainty. Report No. 17/12/ 12. The Hague Centre for Strategic Studies (HCSS), The Hague

De Smet I, White PJ, Bengough AG, Dupuy L, Parizot B, Casimiro I, Heidstra R, Laskowski M, Lepetit M, Hochholdinger F, Draye X, Zhang H, Broadley MR, Peret B, Hammond JP, Fukaki H, Mooney S, Lynch JP, Nacry P, Schurr U, Laplaze L, Benfey P, Beeckman T, Bennett M (2012) Analyzing lateral root development: how to move forward. Plant Cell 24:15-20

Delhaize E, Taylor P, Hocking PJ, Simpson RJ, Ryan PR, Richardson AE (2009) Transgenic barley (Hordeum vulgare L.) expressing the wheat aluminium resistance gene (TaALMT1) shows enhanced phosphorus nutrition and grain production when grown on an acid soil. Plant Biotechnol J 7:391-400

Devaiah BN, Karthikeyan AS, Raghothama KG (2007) WRKY75 transcription factor is a modulator of phosphate acquisition and root development in Arabidopsis. Plant Physiol 143:1789-1801

Devaiah BN, Madhuvanthi R, Karthikeyan AS, Raghothama KG (2009) Phosphate starvation responses and gibberellic acid biosynthesis are regulated by the MYB62 transcription factor in Arabidopsis. Mol Plant 2:43-58

Du Y, Tian J, Liao H, Bai C, Yan X, Liu G (2009) Aluminium tolerance and high phosphorus efficiency helps Stylosanthes better adapt to low-P acid soils. Ann Bot 103:1239-1247

Dubrovsky JG, Forde BG (2012) Quantitative analysis of lateral root development: pitfalls and how to avoid them. Plant Cell 24:4-14

Duff SMG, Sarath G, Plaxton WC (1994) The role of acid phosphatases in plant phosphorus metabolism. Physiol Plant 90:791-800

Ericsson T, Ingestad T (1988) Nutrition and growth of birch seedlings at varied relative phosphorus addition rates. Physiol Plant 72:227-235

Erro J, Zamarreño AM, García-Mina JM (2010) Ability of various water-insoluble fertilizers to supply available phosphorus in hydroponics to plant species with diverse phosphorus-acquisition efficiency: involvement of organic acid accumulation in plant tissues and root exudates. J Plant Nutr Soil Sci 173:772-777

Fang S, Yan X, Liao H (2009) 3D reconstruction and dynamic modeling of root architecture in situ and its application to crop phosphorus research. Plant J 60:1096-1108

Föhse D, Claassen N, Jungk A (1988) Phosphorus efficiency of plants. I. External and internal $\mathrm{P}$ requirement and $\mathrm{P}$ uptake efficiency of different plant species. Plant Soil 110:101-109

Föhse D, Claassen N, Jungk A (1991) Phosphorus efficiency of plants. II. Significance of root radius, root hairs and cationanion balance for phosphorus influx in seven plant species. Plant Soil 132:261-272

Franken P (2012) The plant strengthening root endophyte Piriformospora indica: potential application and the biology behind. Appl Microbiol Biotechnol 96:1455-1464

Frommer WB, Davidson MW, Campbell RE (2009) Genetically encoded biosensors based on engineered fluorescent proteins. Chem Soc Rev 38:2833-2841
Galván GA, Parádi I, Burger K, Baar J, Kuyper TW, Scholten OE, Kik C (2009) Molecular diversity of arbuscular mycorrhizal fungi in onion roots from organic and conventional farming systems in The Netherlands. Mycorrhiza 19:317-328

Galván GA, Kuyper TW, Burger K, Keizer LCP, Hoekstra RF, Kik C, Scholten OE (2011) Genetic analysis of the interaction between Allium species and arbuscular mycorrhizal fungi. Theor Appl Genet 122:947-960

Gamuyao R, Chin J, Pariasca-Tanaka J, Pesaresi P, Catausan S, Dalid C, Slamet-Loedin I, Tecson-Mendoza EM, Wissuwa M, Heuer S (2012) The protein kinase Pstoll from traditional rice confers tolerance of phosphorus deficiency. Nature 488:535-539

Gaxiola RA, Edwards M, Elser JJ (2011) A transgenic approach to enhance phosphorus use efficiency in crops as part of a comprehensive strategy for sustainable agriculture. Chemosphere 84:840-845

Gaxiola RA, Sanchez CA, Paez-Valencia J, Ayre BG, Elser JJ (2012) Genetic manipulation of a "vacuolar" $\mathrm{H}^{+}$-PPase: from salt tolerance to yield enhancement under phosphorus-deficient soils. Plant Physiol 159:3-11

Gong Y, Guo Z, He L, Li J (2011) Identification of maize genotypes with high tolerance or sensitivity to phosphorus deficiency. J Plant Nutr 34:1290-1302

Górny AG, Sodkiewicz T (2001) Genetic analysis of the nitrogen and phosphorus utilization efficiencies in mature spring barley plants. Plant Breed 120:129-132

Gu H, Lalonde S, Okumoto S, Looger LL, Scharff-Poulsen AM, Grossman AR, Kossmann J, Jakobsen I, Frommer WB (2006) A novel analytical method for in vivo phosphate tracking. FEBS Lett 580:5885-5893

Hammond JP, White PJ (2011) Sugar signaling in root responses to low phosphorus availability. Plant Physiol 156:1033-1040

Hammond JP, Broadley MR, White PJ, King GJ, Bowen HC, Hayden R, Meacham MC, Mead A, Overs T, Spracklen WP, Greenwood DJ (2009) Shoot yield drives phosphorus use efficiency in Brassica oleracea and correlates with root architecture traits. J Exp Bot 60:1953-1968

Hammond JP, Broadley MR, Bowen HC, Spracklen WP, Hayden RM, White PJ (2011) Gene expression changes in phosphorus deficient potato (Solanum tuberosum L.) leaves and the potential for diagnostic gene expression markers. PLoS ONE 92:e24606

Hedley MJ, Kirk GJD, Santos MB (1994) Phosphorus efficiency and the forms of soil phosphorus utilized by upland rice cultivars. Plant Soil 158:53-62

Hellgren O, Ingestad T (1996) A comparison between methods used to control nutrient supply. J Exp Bot 47:117-122

Henry A, Chopra S, Clark DG, Lynch JP (2012) Responses to low phosphorus in high and low foliar anthocyanin coleus (Solenostemon scutellarioides) and maize (Zea mays). Funct Plant Biol 39:255-265

Hetrick BAD, Wilson GWT, Cox TS (1992) Mycorrhizal dependence of modern wheat varieties, landraces and ancestors. Can J Bot 70:2032-2040

Hetrick BAD, Wilson GWT, Gill BS, Cox TS (1995) Chromosome location of mycorrhizal responsive genes in wheat. Can J Bot 73:891-897 
Hetrick BAD, Wilson GWT, Todd TC (1996) Mycorrhizal response in wheat cultivars: relationship to phosphorus. Can J Bot 74:19-25

Ho MD, Rosas JC, Brown KM, Lynch JP (2005) Root architectural tradeoffs for water and phosphorus acquisition. Funct Plant Biol 32:737-748

Hoekenga OA, Maron LG, Piñeros MA, Cancado GMA, Shaff J, Kobayashi Y, Ryan PR, Dong B, Delhaize E, Sasaki T, Matsumoto H, Yamamoto Y, Koyama H, Kochian LV (2006) AtALMT1, which encodes a malate transporter, is identified as one of several genes critical for aluminum tolerance in Arabidopsis. Proc Natl Acad Sci USA 103:9738-9743

Hong JJ, Park YS, Bravo A, Bhattarai KK, Daniels DA, Harrison MJ (2012) Diversity of morphology and function in arbuscular mycorrhizal symbioses in Brachypodium distachyon. Planta 236:851-865

Hu B, Zhu C, Li F, Tang J, Wang Y, Lin A, Liu L, Che R, Chu C (2011) LEAF TIP NECROSIS1 plays a pivotal role in the regulation of multiple phosphate starvation responses in rice. Plant Physiol 156:1101-1115

Ingestad T, Ågren GI (1995) Plant nutrition and growth: basic principles. Plant Soil 168:15-20

Ingestad T, Lund AB (1986) Theory and techniques for steady state mineral nutrition and growth of plants. Scand J For Res 1:439-453

Ingram PA, Zhu JM, Shariff A, Davis IW, Benfey PN, Elich T (2012) High-throughput imaging and analysis of root system architecture in Brachypodium distachyon under differential nutrient availability. Philos Trans R Soc Lond B Biol Sci 367:1559-1569

Itoh S, Barber SA (1983) Phosphorus uptake by six plant species as related to root hairs. Agron J 75:457-461

Janos DP (2007) Plant responsiveness to mycorrhizas differs from dependence upon mycorrhizas. Mycorrhiza 17:75-91

Jin J, Wang G, Liu X, Pan X, Herbert SJ (2005) Phosphorus application affects the soybean root response to water deficit at the initial flowering and full pod stages. Soil Sci Plant Nutr 51:953-960

Kaeppler SM, Parke JL, Mueller SM, Senior L, Stuber C, Tracy WF (2000) Variation among maize inbred lines and detection of quantitative trait loci for growth at low phosphorus and responsiveness to arbuscular mycorrhizal fungi. Crop Sci 40:358-364

Kanno S, Yamawaki M, Ishibashi H, Kobayashi NI, Hirose A, Tanoi K, Nussaume L, Nakanishi TM (2012) Development of real-time radioisotope imaging systems for plant nutrient uptake studies. Philos Trans R Soc Lond B Biol Sci 367:1501-1508

Karthikeyan AS, Varadarajan DK, Mukatira UT, D’Urzo MP, Damsz B, Raghothama KG (2002) Regulated expression of Arabidopsis phosphate transporters. Plant Physiol 130:221-233

Kasuga M, Miura S, Shinozaki K, Yamaguchi-Shinozaki K (2004) A combination of the Arabidopsis DREB1A gene and stress-inducible rd29A promoter improved droughtand low-temperature stress tolerance in tobacco by gene transfer. Plant Cell Physiol 45:346-350

Kochian LV (2012) Rooting for more phosphorus. Nature 488:466-467

Kochian LV, Hoekenga OA, Pineros MA (2004) How do crop plants tolerate acid soils? Mechanisms of aluminum tolerance and phosphorous efficiency. Annu Rev Plant Biol 55:459-493

Kohlen W, Ruyter-Spira C, Bouwmeester HJ (2011) Strigolactones: a new musician in the orchestra of plant hormones. Botany 89:827-840

Kuchenbuch R, Jungk A (1982) A method for determining concentration profiles at the soil-root interface by thin slicing rhizospheric soil. Plant Soil 68:391-394

Lambers H, Finnegan PM, Laliberté E, Pearse SJ, Ryan MH, Shane MW, Veneklaas EJ (2011) Phosphorus nutrition of Proteaceae in severely phosphorus-impoverished soils: are there lessons to be learned for future crops? Plant Physiol 156:1058-1066

Lambers H, Cawthray GR, Giavalisco P, Kuo J, Laliberté E, Pearse SJ, Scheible WR, Stitt M, Teste F, Turner BL (2012) Proteaceae from severely phosphorus-impoverished soils extensively replace phospholipids with galactolipids and sulfolipids during leaf development to achieve a high photosynthetic phosphorus-use-efficiency. New Phytol 196:1098-1108

Lambers H, Clements JC, Nelson MN (2013) How a phosphorus-acquisition strategy based on carboxylate exudation powers the success and agronomic potential of lupines (Lupinus, Fabaceae). Am J Bot 100:263-288

Lehmann A, Barto EK, Powell JR, Rillig MC (2012) Mycorrhizal responsiveness trends in annual crop plants and their wild relatives-a meta-analysis on studies from 1981 to 2010. Plant Soil 355:231-250

Li X, Ren A, Han R, Yin L, Wei M, Gao Y (2012) Endophytemediated effects on the growth and physiology of Achnatherum sibiricum are conditional on both $\mathrm{N}$ and $\mathrm{P}$ availability. PLoS ONE 7:e48010

Liang Q, Cheng X, Mei M, Yan X, Liao H (2010) QTL analysis of root traits as related to phosphorus efficiency in soybean. Ann Bot 106:223-234

Liao H, Yan X, Rubio G, Beebe SE, Blair MW, Lynch JP (2004) Genetic mapping of basal root gravitropism and phosphorus acquisition efficiency in common bean. Funct Plant Biol 31:959-970

Liao H, Wan H, Shaff J, Wang X, Yan X, Kochian LV (2006) Phosphorus and aluminum interactions in soybean in relation to aluminum tolerance. Exudation of specific organic acids from different regions of the intact root system. Plant Physiol 141:674-684

Liu G, James D, Thai P (2006) Induction of root hair growth in a phosphorus-buffered culture solution. Agric Sci China 5:370-376

Liu JF, Zhao CY, Ma J, Zhang GY, Li MG, Yan GJ, Wang XF, Ma ZY (2011) Agrobacterium-mediated transformation of cotton (Gossypium hirsutum L.) with a fungal phytase gene improves phosphorus acquisition. Euphytica 181:31-40

López-Arredondo DL, Herrera-Estrella L (2012) Engineering phosphorus metabolism in plants to produce a dual fertilization and weed control system. Nat Biotechnol 30:889-893

López-Arredondo DL, Leyva-González MA, González-Morales SI, López-Bucio J, Herrera-Estrella L (2014) Phosphate nutrition: improving low-phosphate tolerance in crops. Annu Rev Plant Biol 65:95-123

L'taief B, Sifi B, Zaman-Allah M, Horres R, Molina C, Beebe S, Winter P, Kahl G, Drevon J, Lachaal M (2012) Genotypic 
variability for tolerance to salinity and phosphorus deficiency among $\mathrm{N}_{2}$-dependent recombinant inbred lines of common bean (Phaseolus vulgaris). Afr J Microbiol Res 6:4205-4213

Lynch JP (2007) Roots of the second Green Revolution. Aust J Bot 55:493-512

Mack KML, Rudgers JA (2008) Balancing multiple mutualists: asymmetric interactions among plants, arbuscular mycorrhizal fungi, and fungal endophytes. Oikos 117:310-320

Mairhofer S, Zappala S, Tracy SR, Sturrock C, Bennett M, Mooney SJ, Pridmore T (2012) RooTrak: automated recovery of three-dimensional plant root architecture in soil from X-ray microcomputed tomography images using visual tracking. Plant Physiol 158:561-569

McIvor JG, Guppy C, Probert ME (2011) Phosphorus requirements of tropical grazing systems: the northern Australian experience. Plant Soil 349:55-67

McNear DH Jr, McCulley RL (2012) Influence of the Neotyphodium - tall fescue symbiosis on belowground processes. In: Young CA, Aiken GE, McCulley RL, Strickland JR, Schardl CL (eds) Epichloae, endophytes of cool season grasses: implications, utilization and biology Proceedings of the 7th International Symposium on Fungal Endophytes of Grasses, Lexington, Kentucky, USA, 28 June to 1 July 2010. Samuel Roberts Noble Foundation, Ardmore, pp 94-99

Nagel KA, Putz A, Gilmer F, Heinz K, Fischbach A, Pfeifer J, Faget M, Blossfeld S, Ernst M, Dimaki C, Kastenholz B, Kleinert AK, Galinski A, Scharr H, Fiorani F, Schurr U (2012) GROWSCREEN-Rhizo is a novel phenotyping robot enabling simultaneous measurements of root and shoot growth for plants grown in soil-filled rhizotrons. Funct Plant Biol 39:891-904

Nilsson L, Müller R, Nielsen TH (2010) Dissecting the plant transcriptome and the regulatory responses to phosphate deprivation. Physiol Plant 139:129-143

Niu Y, Chai R, Jin G, Wang H, Tang C, Zhang Y (2013) Responses of root architecture development to low phosphorus availability: a review. Ann Bot 112:391-408

Ochoa IE, Blair MW, Lynch JP (2006) QTL analysis of adventitious root formation in common bean under contrasting phosphorus availability. Crop Sci 46:1609-1621

Omacini M, Semmartin M, Pérez LI, Gundel PE (2012) Grassendophyte symbiosis: a neglected aboveground interaction with multiple belowground consequences. Appl Soil Ecol 61:273-279

Oropeza-Aburto A, Cruz-Ramírez A, Acevedo-Hernández GJ, Pérez-Torres CA, Caballero-Pérez J, Herrera-Estrella L (2012) Functional analysis of the Arabidopsis PLDZ2 promoter reveals an evolutionarily conserved low-Pi-responsive transcriptional enhancer element. J Exp Bot 63:2189-2202

Oseni TO, Shongwe NS, Masarirambi MT (2010) Effect of arbuscular mycorrhiza (AM) inoculation on the performance of tomato nursery seedlings in vermiculite. Int $\mathbf{J}$ Agric Biol 12:789-792

Ozturk L, Eker S, Torun B, Cakmak I (2005) Variation in phosphorus efficiency among 73 bread and durum wheat genotypes grown in a phosphorus-deficient calcareous soil. Plant Soil 269:69-80

Pearse SJ, Veneklaas EJ, Cawthray G, Bolland MDA, Lambers H (2007) Carboxylate composition of root exudates does not relate consistently to a crop species' ability to use phosphorus from aluminium, iron or calcium phosphate sources. New Phytol 173:181-190

Rao IM, Terry N (1995) Leaf phosphate status, photosynthesis, and carbon partitioning in sugar beet. IV. Changes with time following increased supply of phosphate to lowphosphate plants. Plant Physiol 107:1313-1321

Rao IM, Arulanantham AR, Terry N (1989) Leaf phosphate status, photosynthesis, and carbon partitioning in sugar beet. II. Diurnal changes in sugar phosphates, adenylates, and nicotinamide nucleotides. Plant Physiol 90:820-826

Rath M, Salas J, Parhy B, Norton R, Menakuru H, Sommerhalter M, Hatlstad G, Kwon JY, Allan DL, Vance CP, UhdeStone C (2010) Identification of genes induced in proteoid roots of white lupin under nitrogen and phosphorus deprivation, with functional characterization of a formamidase. Plant Soil 334:137-150

Richardson AE, Lynch JP, Ryan PR, Delhaize E, Smith FA, Smith SE, Harvey PR, Ryan MH, Veneklaas EJ, Lambers H, Oberson A, Culvenor RA, Simpson RJ (2011) Plant and microbial strategies to improve the phosphorus efficiency of agriculture. Plant Soil 349:121-156

Rose TJ, Wissuwa M (2012) Rethinking internal phosphorus utilization efficiency: a new approach is needed to improve PUE in grain crops. Adv Agron 116:185-217

Rose TJ, Pariasca-Tanaka J, Rose MT, Fukuta Y, Wissuwa M (2010) Genotypic variation in grain phosphorus concentration, and opportunities to improve P-use efficiency in rice. Field Crops Res 119:154-160

Russchen HJ, Wander J, Malda JT (2012) Phosphate usage in arable fields. How can phosphate in arable fields be mobilized for the benefit of crop growth? [Dutch]. DLV Plant BV/ALTIC/Productschap Akkerbouw PA/Masterplan Mineralenmanagement MMM, Dronten

Ruyter-Spira C, Bouwmeester H (2012) Strigolactones affect development in primitive plants. The missing link between plants and arbuscular mycorrhizal fungi? New Phytol 195:730-733

Sain SL, Barnes DK, Biesboer DD (1994) Hydroponic and tissue culture evaluation of alfalfa (Medicago sativa L.) subpopulations selected for phosphorus efficiency. Plant Sci 99:17-26

Sasaki T, Yamamoto Y, Ezaki B, Katsuhara M, Ahn S, Ryan PR, Delhaize E, Matsumoto H (2004) A wheat gene encoding an aluminum-activated malate transporter. Plant $\mathrm{J}$ 37:645-653

Sattari SZ, Bouwman AF, Giller KE, Van Ittersum MK (2012) Residual soil phosphorus as the missing piece in the global phosphorus crisis puzzle. Proc Natl Acad Sci USA 109:6348-6353

Sattari SZ, Van Ittersum MK, Giller KE, Zhang F, Bouwman AF (2014) Key role of China and its agriculture in global sustainable phosphorus management. Environ Res Lett 9:054003

Sawers RJH, Gutjahr C, Paszkowski U (2008) Cereal mycorrhiza: an ancient symbiosis in modern agriculture. Trends Plant Sci 13:93-97

Sawers RJH, Gebreselassie MN, Janos DP, Paszkowski U (2010) Characterizing variation in mycorrhiza effect among diverse plant varieties. Theor Appl Genet 120:1029-1039 
Schüller H (1969) The CAL method, a new technique for determining plant-available phosphorus In soils. Zeitschrift fur Pflanzenernährung und Bodenkunde 123:48-63

Shane MW, Lambers H (2005) Cluster roots: a curiosity in context. Plant Soil 274:101-125

Shi L, Shi T, Broadley MR, White PJ, Long Y, Meng J, Xu F, Hammond JP (2013) High-throughput root phenotyping screens identify genetic loci associated with root architectural traits in Brassica napus under contrasting phosphate availabilities. Ann Bot 112:381-389

Smit AL, Bindraban PS, Schröder JJ, Conijn JG, van der Meer HG (2009) Phosphorus in agriculture: global resources, trends and developments: report to the steering committee technology assessment of the ministery of agriculture, nature and food quality, The Netherlands. Plant Research International Report 282. Plant Research International, Wageningen, 42 pp. http://edepot.wur.nl/12571

Smith SE, Smith FA (2011) Roles of arbuscular mycorrhizas in plant nutrition and growth: new paradigms from cellular to ecosystem scales. Annu Rev Plant Biol 62:227-250

Smith SE, Smith FA (2012) Fresh perspectives on the roles of arbuscular mycorrhizal fungi in plant nutrition and growth. Mycologia 104:1-13

Smith SE, Jakobsen I, Gronlund M, Smith FA (2011) Roles of arbuscular mycorrhizas in plant phosphorus nutrition: interactions between pathways of phosphorus uptake in arbuscular mycorrhizal roots have important implications for understanding and manipulating plant phosphorus acquisition. Plant Physiol 156:1050-1057

Su J, Xiao Y, Li M, Liu Q, Li B, Tong Y, Jia J, Li Z (2006) Mapping QTLs for phosphorus-deficiency tolerance at wheat seedling stage. Plant Soil 281:25-36

Sulpice R, Ishihara H, Schlereth A, Cawthray GR, Encke B, Giavalisco P, Ivakov A, Arrivault S, Jost R, Krohn N, Kuo J, Laliberté E, Pearse SJ, Raven JA, Scheible WR, Teste F, Veneklaas EJ, Stitt M, Lambers H (2014) Low levels of ribosomal RNA partly account for the very high photosynthetic phosphorus-use efficiency of Proteaceae species. Plant, Cell Environ 37:1276-1298

Sun HH, Scharff-Poulsen AM, Gu H, Jakobsen I, Kossmann JM, Frommer WB, Almdal K (2008) Phosphate sensing by fluorescent reporter proteins embedded in polyacrylamide nanoparticles. ACS Nano 2:19-24

Syers JK, Johnston AE, Curtin D (2008) Efficiency of soil and fertilizer phosphorus use: reconciling changing concepts of soil phosphorus behaviour with agronomic information. FAO Fertilizer and Plant Nutrition Bulletin; 2008 18. Food and Agriculture Organization of the United Nations (FAO), Rome

Tang H, Li X, Zu C, Zhang F, Shen J (2013) Spatial distribution and expression of intracellular and extracellular acid phosphatases of cluster roots at different developmental stages in white lupin. J Plant Physiol 170:1243-1250

Tian JA, Venkatachalam P, Liao H, Yan X, Raghothama K (2008) Molecular cloning and characterization of phosphorus starvation responsive genes in common bean (Phaseolus vulgaris L.). Planta 227:151-165

Tian J, Wang X, Tong Y, Chen X, Liao H (2012) Bioengineering and management for efficient phosphorus utilization in crops and pastures. Curr Opin Biotechnol 23:866-871
Trachsel S, Kaeppler SM, Brown KM, Lynch JP (2011) Shovelomics: high throughput phenotyping of maize (Zea mays L.) root architecture in the field. Plant Soil 341:75-87

Trolove SN, Hedley MJ, Caradus JR, Mackay AD (1996) Uptake of phosphorus from different sources by Lotus pedunculatus and three genotypes of Trifolium repens. 1. Plant yield and phosphate efficiency. Aust J Soil Res 34:1015-1026

Uwimana B, Smulders MJM, Hooftman DAP, Hartman Y, van Tienderen PH, Jansen J, McHale LK, Michelmore RW, van de Wiel CCM, Visser RGF (2012) Hybridization between crops and wild relatives: the contribution of cultivated lettuce to the vigour of crop-wild hybrids under drought, salinity and nutrient deficiency conditions. Theor Appl Genet 125:1097-1111

Vaccari DA (2009) Phosphorus: a looming crisis. Sci Am 300:42-47

Vance CP, Uhde-Stone C, Allan DL (2003) Phosphorus acquisition and use: critical adaptations by plants for securing a nonrenewable resource. New Phytol 157:423-447

Veneklaas EJ, Lambers H, Bragg J, Finnegan PM, Lovelock CE, Plaxton WC, Price CA, Scheible WR, Shane MW, White PJ, Raven JA (2012) Opportunities for improving phosphorus-use efficiency in crop plants. New Phytol 195:306-320

Verbruggen E, van de Heijden MGA, Weedon JT, Kowalchuk GA, Röling WFM (2012) Community assembly, species richness and nestedness of arbuscular mycorrhizal fungi in agricultural soils. Mol Ecol 21:2341-2353

Vinod KK, Heuer S (2012) Approaches towards nitrogen- and phosphorus-efficient rice. AoB Plant 2012:pls028

Walk TC, Jaramillo R, Lynch JP (2006) Architectural tradeoffs between adventitious and basal roots for phosphorus acquisition. Plant Soil 279:347-366

Wan Y, Zhu L, Yang S, Yang Z, Zhu W (2010) Effects of P deficiency on protective enzyme activity and membrane lipid peroxidation in different tomato genotypes. Acta Hortic 856:113-120

Wang YH, Garvin DF, Kochian LV (2002) Rapid induction of regulatory and transporter genes in response to phosphorus, potassium, and iron deficiencies in tomato roots. Evidence for cross talk and root/rhizosphere-mediated signals. Plant Physiol 130:1361-1370

Wang L, Liao H, Yan X, Zhuang B, Dong Y (2004) Genetic variability for root hair traits as related to phosphorus status in soybean. Plant Soil 261:77-84

Wang X, Yan X, Liao H (2010) Genetic improvement for phosphorus efficiency in soybean: a radical approach. Ann Bot 106:215-222

White PJ, Veneklaas EJ (2012) Nature and nurture: the importance of seed phosphorus content. Plant Soil 357:1-8

Yan X, Liao H, Beebe SE, Blair MW, Lynch JP (2004) QTL mapping of root hair and acid exudation traits and their relationship to phosphorus uptake in common bean. Plant Soil 265:17-29

Yan HL, Liu WK, Liu X, Li GH, Zhang SX (2010) Comparison of rhizosphere impacts of two wheat genotypes differing in phosphorus utilization efficiency. Can J Plant Sci 90:311-317 
Yi K, Menand B, Bell E, Dolan L (2010) A basic helix-loophelix transcription factor controls cell growth and size in root hairs. Nat Genet 42:264-267

Zhang D, Cheng H, Geng L, Kan G, Cui S, Meng Q, Gai J, Yu D (2009) Detection of quantitative trait loci for phosphorus deficiency tolerance at soybean seedling stage. Euphytica 167:313-322

Zhang D, Liu C, Cheng H, Kan G, Cui S, Meng Q, Gai J, Yu D (2010) Quantitative trait loci associated with soybean tolerance to low phosphorus stress based on flower and pod abscission. Plant Breed 129:243-249

Zhang D, Song H, Cheng H, Hao D, Wang H, Kan G, Jin H, Yu D (2014) The acid phosphatase-encoding gene GmACP1 contributes to soybean tolerance to low-phosphorus stress. PLoS Genet 10:e1004061
Zhu JM, Kaeppler SM, Lynch JP (2005) Mapping of QTLs for lateral root branching and length in maize (Zea mays L.) under differential phosphorus supply. Theor Appl Genet 111:688-695

Zhu JM, Brown KM, Lynch JP (2010) Root cortical aerenchyma improves the drought tolerance of maize (Zea mays L.). Plant, Cell Environ 33:740-749

Zoysa AKN, Loganathan P, Hedley MJ (1997) A technique for studying rhizosphere processes in tree crops: soil phosphorus depletion around camellia (Camellia japonica L.) roots. Plant Soil 190:253-265

Zoysa AKN, Loganathan P, Hedley MJ (1999) Phosphorus utilisation efficiency and depletion of phosphate fractions in the rhizosphere of three tea (Camellia sinensis L.) clones. Nutr Cycl Agroecosyst 53:189-201 